\title{
Understanding cage effects in the $n$-alkane conversion on zeolites
}

\author{
Theo L.M. Maesen ${ }^{\mathrm{a}, *}$, Edith Beerdsen ${ }^{\mathrm{b}}$, Sofia Calero ${ }^{\mathrm{c}}$, David Dubbeldam ${ }^{\mathrm{b}}$, Berend Smit ${ }^{\mathrm{b}, \mathrm{d}}$ \\ ${ }^{a}$ Chevron, Energy Technology Company, 100 Chevron Way 10-1412, Richmond, CA 94802-0627, USA \\ b Van't Hoff Institute for Molecular Sciences, University of Amsterdam, Nieuwe Achtergracht 166, 1018 WV Amsterdam, The Netherlands \\ ${ }^{c}$ Department of Experimental Science, University Pablo de Olavide, Ctra de Utrera, Km. 1, 41013 Seville, Spain \\ ${ }^{\mathrm{d}}$ European Centre for Atomic and Molecular Computations (CECAM), Ecole Normale Supérieure (ENS), 46, Allée d'Italie, 69007 Lyon, France
}

Received 31 August 2005; revised 7 November 2005; accepted 9 November 2005

Available online 15 December 2005

\begin{abstract}
Molecular simulations are used to provide insight into published catalytic reactivity data for zeolites that exhibit a cage effect, the selective and preferential conversion of short-chain rather than long-chain $n$-alkanes. This paper demonstrates that understanding cage effects for ERI-, AFX-, and FER-type zeolites requires consideration of four components: (1) adsorption thermodynamics, (2) adsorption kinetics, (3) conversion at the exterior surface of the catalysts, and (4) coke-induced modifications to the pore texture. By breaking down the Gibbs free energy of adsorption into its enthalpic and entropic contributions, we can further elucidate the influence of the zeolite topology on the adsorption of $n$-alkanes with different hydrocarbon chain lengths. This analysis indicates that zeolite topologies with cages accessible through windows $<0.47 \mathrm{~nm}$ wide are particularly prone to exhibiting a cage effect, because they impose a high thermodynamic penalty on the adsorption of molecules that are too long to fit comfortably in a single cage. This improved understanding of the cage effect could facilitate its renewed use in commercial practice.
\end{abstract}

(C) 2005 Elsevier Inc. All rights reserved.

Keywords: ERI-, AFX-, FER-type zeolites; $n$-Alkane conversion; Cage effects; Shape selectivity; Enthalpy-entropy compensation; $n$-Pentacosane

\section{Introduction}

For the fourth time in a century [1], ethanol has become a gasoline additive in the United States. The addition of ethanol displaces the most volatile compounds in the gasoline pool to meet front-end volatility specifications. Previous attempts at compensating for a similar shift in composition [1] coincided with the commercialization of the Selectoforming process [2]. This light-naphtha reforming process selectively hydrocracks short-chain $n$-pentane and $n$-hexane, removing them from the gasoline pool to yield liquid petroleum gas (LPG). The overall effect on the gasoline pool is one of reduced volatility and increased octane number [3-5]. The resulting high-octane gasoline is compatible with high-compression engines and their concomitant advantage of increased mileage. In principle, these improved-mileage automobiles afforded an adequate response to the high gasoline prices of the 1970s [2]. At the time of

\footnotetext{
* Corresponding author.

E-mail address: tmaesen@ chevron.com (T.L.M. Maesen).
}

writing, ethanol has been reintroduced in the gasoline pool, and gasoline prices are back on the increase, so the Selectoforming process could be of renewed value, especially where an associated market exists for LPG.

Undoubtedly, the resurrection of a process that uses a zeolite to selectively hydrocrack the short-chain $n$-alkanes would benefit from a better understanding of its unusual selectivity [6]. Usually catalysts selectively convert the long-chain rather than the short-chain $n$-alkanes [6-21]. When catalysts exhibiting the inverse selectivity were first discovered, this selectivity was dubbed a "cage effect" [22-29]; later, it was termed "secondary shape selectivity" [30,31]. In this paper we revert to the earlier nomenclature.

Naturally, a cage effect represents the effect of a specific aspect of a zeolite topology (cage) on the reactant slate. By definition, this is an instance of reactant shape selectivity. Classical shape selectivity theory [32-35] focuses on the effect of a zeolite topology on the barriers to adsorption (reactant shape selectivity), reaction (transition state shape selectivity), and desorption (product shape selectivity). In line with the classical concept of reactant shape selectivity, traditional explanations 
for the cage effect have focused exclusively on the effect of zeolite topology on the barrier to adsorption [22-31]. In this paper we show that the difference in Gibbs free energy level between gas and adsorbed phase (viz. the Gibbs free energy of adsorption) is at least as important as the ease of transition from gas phase to adsorbed phase. Note that when we discuss Gibbs free energy of adsorption, "lower" is synonymous with "more negative," and a lower Gibbs free energy of adsorption translates into a higher reactivity.

Most studies on the effect of the Gibbs free energy of adsorption on zeolite catalysis discuss its effect on activity [6-19, $21,36]$, not on selectivity. These studies have clearly established that reactivity increases with increasing $n$-alkane chain length, mainly because the Gibbs free energy of adsorption decreases linearly with $n$-alkane chain length, and-by the same token - the adsorption constant increases exponentially [6-19, 21,37-40]. At pressures above the $n$-alkane saturation pressure, this steady decrease in Gibbs free energy of adsorption with increasing $n$-alkane chain length can inverse, resulting in the preferential adsorption and conversion of the shorter-chain instead of the longer-chain $n$-alkane [41-48]. High pressure can induce this selectivity inversion because it enhances the importance of intermolecular interactions at the expense of molecule-wall interactions. When the intermolecular interactions dominate the Gibbs free energy of adsorption, short-chain $n$-alkanes can exhibit a lower Gibbs free energy of adsorption than long-chain $n$-alkanes, because the former can pack more efficiently (in more conformations, with more mobility) and therefore lose less entropy on adsorption [42-48]. This pressure-induced selectivity inversion is beyond the scope of this paper. For the purposes of this paper, we define a cage effect as the preference for converting the short-chain instead of long-chain $n$-alkanes as a result of molecule-wall interactions, that is, as a form of reactant shape selectivity that occurs irrespective of pressure and loading.

Since its inception, a cage effect has been intimately linked to a window effect [49]. A window effect refers to the proportionality between the diffusion rate and the commensurateness of the shape of the adsorbent and the shape of the adsorbate [13, 49-55]. Such a phenomenon was already known as "incommensurate diffusion" in physics [56], but was renamed "resonance diffusion" in catalysis [51]. In catalysis the existence of incommensurate diffusion remains controversial, highlighting the experimental difficulties in obtaining consistent diffusion rates [54,57-62]. In this paper we show that incommensurate diffusion in ERI-type zeolites is a prerequisite to understanding these zeolites' remarkable reactant shape selectivity in $n$-alkane hydroconversion.

As part of a systematic study of shape selectivity, we build on earlier work [15] in attempting to combine the impact of a topology on the adsorption kinetics with that on adsorption thermodynamics to obtain a more complete understanding of shape selectivity $[63,64]$. This leads to a definition for reactant shape selectivity as the preferential conversion of (i) the reactant that combines the highest diffusion rate with the lowest (i.e., most negative) Gibbs free energy of adsorption when the reaction is diffusion-limited and (ii) the reactant with the lowest Gibbs free energy of adsorption when a reaction is not diffusion-limited. Analyses of cage effects in ERI-, AFX-, and FER-type zeolite provide illustrative examples of the application of this novel concept. Because the Gibbs free energy of adsorption plays a major role in inducing a cage effect, an analysis of the adsorption properties of many topologies affords categorization according to the propensity of these topologies to induce a cage effect.

\section{Molecular simulation methods}

Because natural ERI-type zeolites are strong human carcinogens [65], we emphasize that all simulations were done in silico, so that all zeolites were safely contained in virtual reality. It is possible that synthetic ERI-type zeolites (made as described previously [66]) are less fibrous and thus safer than their natural counterparts [65]. However, it seems a safer choice to replace the ERI-type zeolites with synthetic CHA-type zeolites in experimental studies. CHA-type zeolites do not come as asbestos-like fibrous crystals, are available in a wider range of chemical compositions [67-70] than ERI-type zeolites, and yet exhibit catalytic and adsorption properties that closely parallel those of ERI-type zeolites [59,71-73].

At the molecular level, detailed information about the adsorbed hydrocarbons is needed to study the driving forces behind shape selectivity. We obtain this information using computer simulations based on the configurational-bias Monte Carlo (CBMC) technique. The CBMC technique enables efficient calculation of the thermodynamic properties and adsorption isotherms of hydrocarbons in nanoporous silica structures $[47,74,75]$. In the CBMC scheme, the molecules are grown bead-by-bead, biasing the growth toward energetically more favorable conformations and thus avoiding overlaps with the zeolite. This results in a sampling scheme that is orders of magnitude more efficient than traditional Monte Carlo schemes, in which entire molecules are inserted at once, generating a high percentage of unlikely or impossible configurations in the process. Because of its efficiency, the CBMC scheme allows us to obtain information about hydrocarbons as large as pentaeicosane $\left(\mathrm{C}_{25}\right)$.

Our CBMC simulations model uses single interaction centers (united atoms) to represent the $\mathrm{CH}_{3}, \mathrm{CH}_{2}, \mathrm{CH}$, and $\mathrm{C}$ groups in the linear and branched alkanes. The bonded interactions include bond-bending and torsion potentials. Dispersive interactions with the oxygen atoms of the silica structure are assumed to dominate the silica-alkane interactions. The zeolite is modeled as a rigid crystal [76] consisting exclusively of $\mathrm{SiO}_{2}$, so as to make the calculation of alkane-zeolite interactions efficient using special interpolation techniques [77,78]. The sizes of the molecules and the energy parameters have been chosen to faithfully reproduce the experimentally determined isotherms (particularly the inflection points) on MFI-type zeolites over a wide range of pressures and temperatures [74,75]. The resultant force field reproduces the Henry coefficients, enthalpies and entropies of adsorption, and maximum loading extremely well $[74,75]$. The same force field also reproduces these parameters remarkably well for nanoporous silica topologies other than the 
MFI type [74,75]. More details about the simulation method and the force fields have been provided elsewhere [74,75].

Gibbs free energies and enthalpies of condensation at $605 \mathrm{~K}$ were extrapolated from $n$-alkane vapor pressures (assuming that the pressure equals the fugacity), and enthalpies of vaporization that were determined experimentally in the temperature range 509-559 K [79]. Gibbs free energy and enthalpy enable calculation of the entropy of condensation.

Acid site densities of the AFX-, FER-, and MFI-type zeolites discussed were calculated from previously reported bulk silicon-to-aluminium ratios [16,30,31], assuming that each aluminium is part of the zeolite framework and generates an acid site. Apparent (or observed) reaction rate constants $k^{\prime}$ $\left(\mathrm{m}_{\mathrm{gas}}^{3} /\left(\mathrm{m}_{\mathrm{ads}}^{3} \mathrm{~s}\right)\right)$ were calculated from the conversion $X$ (1) using

$-\ln (1-X)=k^{\prime} \frac{3.6 c_{\mathrm{A} 0} M}{\rho \mathrm{WHSV}}$.

In this equation, $3.6(\mathrm{~s} \mathrm{~kg} /(\mathrm{hg}))$ is a factor that puts the units on a consistent basis, $c_{\mathrm{A} 0}\left(\mathrm{~mol} / \mathrm{m}_{\mathrm{gas}}^{3}\right)$ is the initial $n$-alkane concentration in the gas phase, $M(\mathrm{~g} / \mathrm{mol})$ is the $n$-alkane molecular weight, $\rho\left(\mathrm{kg}_{\mathrm{ads}} / \mathrm{m}_{\mathrm{ads}}^{3}\right)$ is the zeolite framework density, and WHSV $\left(\mathrm{kg}_{\text {gas }} /\left(\mathrm{kg}_{\text {ads }} \mathrm{h}\right)\right)$ is the weight hourly space velocity of the $n$-alkane feed. It is convenient to define an apparent contact time $\tau^{\prime}\left(\mathrm{s} \mathrm{m}_{\mathrm{ads}}^{3} / \mathrm{m}_{\mathrm{gas}}^{3}\right)$ as $\tau^{\prime} \equiv 3.6 c_{\mathrm{A} 0} M /(\rho \mathrm{WHSV})$.

In the Henry regime and in the absence of diffusion limitations, the relationship between observed reaction rate constant $k^{\prime}$ and the intrinsic reaction rate constant $k(1 / \mathrm{s})$ is $[16,17]$ (see Appendix A),

$k^{\prime}=\rho K_{\mathrm{H}} R T k$.

In this equation, $K_{\mathrm{H}}\left(\mathrm{mol} /\left(\mathrm{kg}_{\mathrm{ads}} \mathrm{Pa}\right)\right)$ is the Henry coefficient, $R\left(=8.3144 \mathrm{~Pa} \mathrm{~m}_{\text {gas }}^{3} /(\mathrm{mol} \mathrm{K})\right)$ is the gas constant, and $T(\mathrm{~K})$ is the temperature.

When the reaction is severely diffusion-limited, the relationship between observed reaction rate constant $k^{\prime}$ and the intrinsic reaction rate constant $k$ is (see Appendix B)

$k^{\prime}=\rho K_{\mathrm{H}} R T \frac{1}{\delta} \sqrt{k D}$.

In this equation, $\delta(\mathrm{m})$ is the crystal radius of an ERI- or AFXtype crystal or half the length of a FER-type channel, and $D$ $\left(\mathrm{m}^{2} / \mathrm{s}\right)$ is the Fick diffusion coefficient.

Henry coefficient and Gibbs free energy of adsorption, $\Delta G_{\text {ads }}(\mathrm{J} / \mathrm{mol})$, are related as [75]

$\Delta G_{\text {ads }}=-R T\left\{1+\ln \left(\rho K_{\mathrm{H}} R T\right)\right\}$.

Previously $[64,80]$ we approximated the Gibbs free energy with the Helmholtz free energy. Equation (4) is exact.

\section{Results and discussion}

\subsection{Diffusion and adsorption combine to yield a cage effect for ERI-type zeolites}

For most zeolites and amorphous catalysts studied, the reactivity of $n$-alkanes increases with increasing $n$-alkane length,

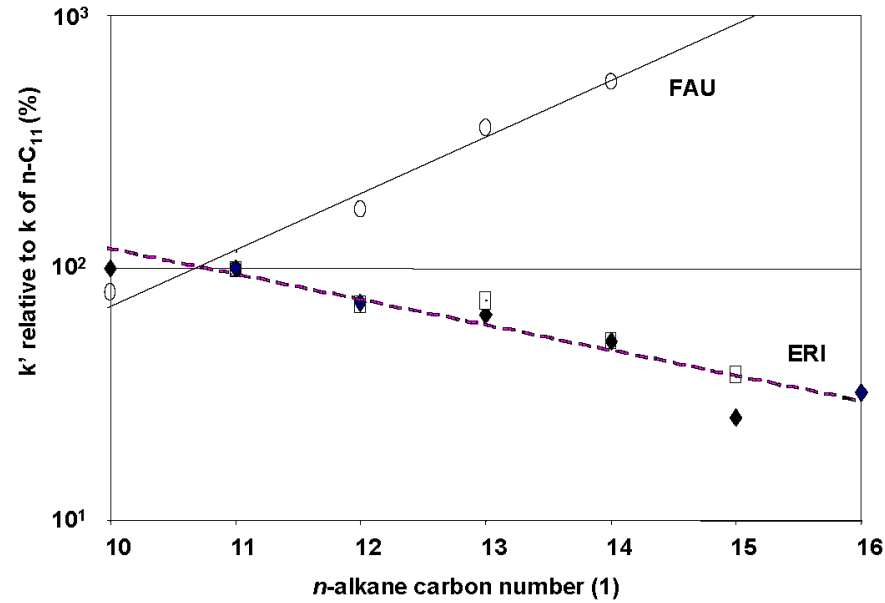

Fig. 1. The change in $n$-alkane hydroconversion activity with $n$-alkane chain length on Pt-loaded ERI-type zeolites at 670-700 K (,$\square$ ) (data adapted from Chen and Garwood [23,25], experimental conditions described in Table 1) is the inverse of that observed on Pt-loaded FAU-type zeolites at $513 \mathrm{~K}(\mathrm{O})$ (data obtained by Debrabandere and Froment at conditions in the range of $500 \mathrm{kPa} \leqslant$ total pressure $\leqslant 7000 \mathrm{kPa} ; 20 \mathrm{~g}_{\text {cat }} \mathrm{h} / \mathrm{mol} \leqslant$ space time $\leqslant 200 \mathrm{~g}_{\text {cat }} \mathrm{h} / \mathrm{mol} ; 30 \mathrm{~mol} / \mathrm{mol} \leqslant \mathrm{H}_{2} / n$-alkane $\leqslant 400 \mathrm{~mol} / \mathrm{mol}$ [18]). To guide the eye, least squares regression lines were added for ERI- and FAU-type zeolites: $100 \times k^{\prime} / k_{n-\mathrm{C}_{11}}^{\prime}=1203 \mathrm{e}^{-0.23 \mathrm{CN}}$ and $=0.42 \mathrm{e}^{+0.51 \mathrm{CN}}(\mathrm{CN}(1), n$-alkane carbon number), respectively.

because their Gibbs free energy of adsorption decreases linearly with their chain length and, by the same token, their adsorption constant increases exponentially with increasing chain length (Fig. 1) [10-19,37-39]. ERI-type zeolites afforded the first example of the inverse order in reactivity, because in ERI-type zeolites the $n$-alkane reactivity decreases monotonically with increasing $n$-alkane length from $n$-decane $\left(n-\mathrm{C}_{10}\right)$ to $n$-hexadecane $\left(n-\mathrm{C}_{16}\right)$ (Fig. 1) [23-25,28]. The historic explanation for this phenomenon is that the reactivity decreases due to a strong decrease of the diffusion rate with $n$-alkane length [23-28]. However, this explanation is at variance with the simultaneously reported marked increase in diffusion rate with increasing $n$-alkane length from $n-\mathrm{C}_{10}$ to $n$ - $\mathrm{C}_{12}[23-25,28,50]$. Recent molecular simulations corroborate this increase in diffusion rate and highlight the need to consider the effect of both diffusion and adsorption constants on reactant shape selectivity $[59,72$, 73]. Determining how to combine diffusion and adsorption constants requires a closer look at the $n$-alkane hydroconversion kinetics.

It has been suggested that the $n$-alkane hydroconversion on ERI-type zeolites is first-order in $n$-alkane and diffusion-limited at the conditions under discussion [23]. Consistent with firstorder kinetics, the conversion is independent of the partial pressure of the individual $n$-alkanes (Table 4) [23-25]. First-order kinetics implies that the reaction rate is directly proportional to the $n$-alkane partial pressure, because the $n$-alkane loading of the zeolite pores is extremely low $[7,13,15]$. Molecular simulations on the adsorption of $n$-tridecane $\left(n-\mathrm{C}_{13}\right.$, taken as representative for the $n-\mathrm{C}_{10}-n-\mathrm{C}_{16}$ reactant slate) corroborate that ERI-type zeolites indeed require a significantly higher $n$-alkane pressure than, say, FER-type zeolites before they fill up with these relatively long $n$-alkanes (Fig. 2). The reason for this high 
Table 1

Published apparent $n$-alkane hydroconversion rate constant $k^{\prime}\left(\mathrm{m}_{\mathrm{gas}}^{3} /\left(\mathrm{m}_{\text {ads }}^{3} \mathrm{~s}\right)\right)$ obtained by processing various mixed feeds on ERI-type zeolites at two temperatures $T(\mathrm{~K})$, hydrogen pressures $p_{\mathrm{H}_{2}}(\mathrm{kPa})$, hydrocarbon pressures $p_{\mathrm{HC}}$ $(\mathrm{kPa})$, and hydrogen-to-hydrocarbon ratios, $\mathrm{H}_{2} / \mathrm{HC}(\mathrm{mol} / \mathrm{mol})$ (data adapted from Chen and Garwood [23,25]). The feed composition is described by mol\% $n$-alkane of the total $n$-alkane fraction. Apparent rate constants were normalized relative to that of $n-\mathrm{C}_{11}$

\begin{tabular}{lccc}
\hline & \multicolumn{3}{c}{ Data source } \\
\cline { 2 - 4 } & {$[25]$} & {$[23]$} & {$[23]$} \\
\hline$T(\mathrm{~K})$ & 672 & 672 & 733 \\
$p_{\mathrm{H}_{2}}(\mathrm{kPa})$ & 13297 & 13297 & 1336 \\
$p_{\mathrm{HC}}(\mathrm{kPa})$ & 492 & 492 & 44 \\
$\mathrm{H}_{2} / \mathrm{HC}$ & 27 & 27 & 30
\end{tabular}

( $\mathrm{mol} / \mathrm{mol})$

\begin{tabular}{lcrrrrr} 
& $\begin{array}{c}\text { mol\% } \\
n-\mathrm{C}_{10}\end{array}$ & Rel. $k^{\prime}$ & mol\% & Rel. $k^{\prime}$ & $\begin{array}{l}\text { mol\% } \\
22.6\end{array}$ & $\begin{array}{l}\text { Rel. } k^{\prime} \\
100\end{array}$ \\
$n-\mathrm{C}_{11}$ & 1.5 & & & & & \\
$n-\mathrm{C}_{12}$ & 12.1 & 100 & 19.4 & 100 & & 78 \\
$n-\mathrm{C}_{13}$ & 33.4 & 71 & 36.5 & 70 & 18.8 & \\
$n-\mathrm{C}_{14}$ & 32.5 & 74 & 32.8 & 68 & & \\
$n-\mathrm{C}_{15}$ & 13.2 & 51 & 8.1 & 47 & 16.2 & 59 \\
$n-\mathrm{C}_{16}$ & 5.2 & 37 & 3.2 & 40 & & \\
\hline
\end{tabular}

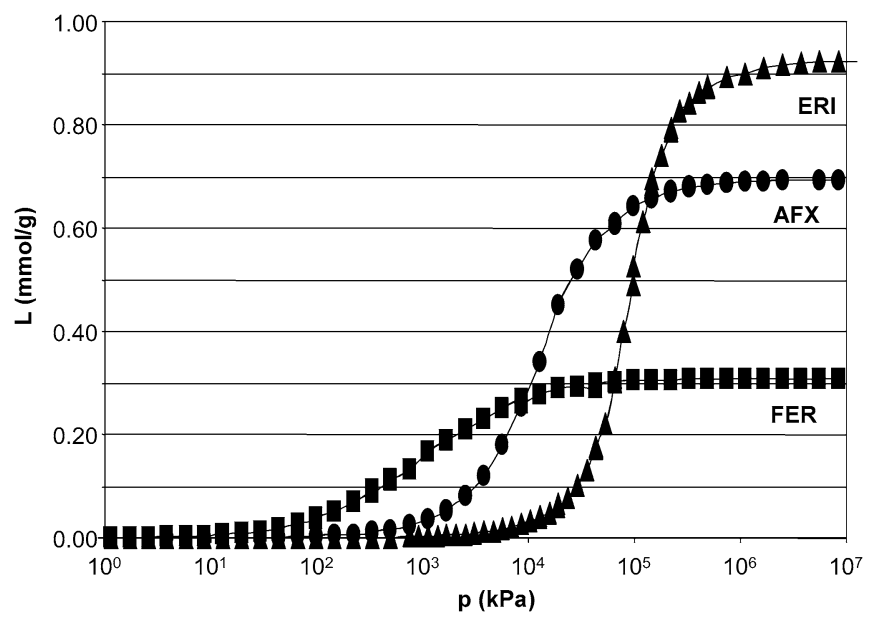

Fig. 2. $n-\mathrm{C}_{13}$ adsorption isotherms at $670 \mathrm{~K}$ on ERI- $(\boldsymbol{\Delta})$, AFX- $(\bullet)$ and FERtype ( $\boldsymbol{\square})$ illustrate how a lower Gibbs free energy of adsorption (decreases in the order of ERI $>$ AFX $>$ FER) in the Henry regime corresponds to a higher required filling pressure.

resistance to absorbing these relatively long $n$-alkanes is that they do not fit inside a single ERI-type cage, so that they always have to squeeze through an ERI-type window [59,72,73] (Fig. 3). ERI-type windows are so narrow that they exert repulsive van der Waals interactions that increase the Gibbs free energy of adsorption [59,72,73]. The pores of the FER-type zeolites are wide enough not to exert these repulsive van der Waals interactions, and they fill up at significantly lower pressures (Fig. 2).

At sufficiently low loading, the diffusion rate through the ERI-type pores is not a function of loading [62,81]. Furthermore, the intrinsic rate constant, $k(1 / \mathrm{s})$, is not a strong function of $n$-alkane length $[19,20]$. In this case the first-order diffusion-limited disappearance of $n$-alkane will be proportional to the product of the Henry constant, $K_{\mathrm{H}}(\mathrm{mol} /(\mathrm{kg} \mathrm{Pa}))$, and the square root of the diffusion constant, $D\left(\mathrm{~m}^{2} / \mathrm{s}\right)$, that is, to $K_{\mathrm{H}} \sqrt{D}$ [7] (see Eq. (3) and Appendix B). Fig. 4 illustrates that the decrease in $K_{\mathrm{H}} \sqrt{D}$ with $n$-alkane length reproduces the monotonic decrease in reactivity with $n$-alkane length significantly better than either $K_{\mathrm{H}}$ or $D$ in isolation. It has been argued that the diffusion constant decreases monotonically with $n$-alkane length $[57,58]$. Combined with the simulated $K_{\mathrm{H}}$, this would result in a decidedly nonmonotonic variation in $K_{\mathrm{H}} \sqrt{D}$ with $n$-alkane length, which would be at variance with the monotonic decrease in activity with $n$-alkane length reported in catalytic experiments (Fig. 4). Although combination of simulated $K_{\mathrm{H}}$ and simulated $D$ into $K_{\mathrm{H}} \sqrt{D}$ reproduces the monotonic decrease in activity with $n$-alkane length, the fit is not perfect; the decrease in $K_{\mathrm{H}} \sqrt{D}$ with $n$-alkane length is faster than that of the published reaction rate-constant $k^{\prime}$. A likely reason for this discrepancy is that the monotonic decrease in $K_{\mathrm{H}} \sqrt{D}$ with chain length at the interior surface is partially offset by a monotonic increase in $K_{\mathrm{H}}$ with chain length at the exterior crystal surface. Both $K_{\mathrm{H}}$ and $D$ at the interior surface are extremely low [58,59], so that adsorption and reaction at the exterior surface of the ERI-type zeolites are likely to make a significant contribution to overall hydroconversion activity.

\subsection{Adsorption yields a cage effect for AFX-type zeolites}

Similar to ERI-type zeolites, AFX-type zeolites preferentially convert the shorter-chain $n$-alkane instead of the longerchain $n$-alkane when converting a mixture of short-chain and long-chain $n$-alkanes [30]. The preference of both of these zeolites for converting short-chain instead of long-chain $n$-alkanes is no surprise, because both topologies consist of narrow windows providing access to large cages (Fig. 3) [70]. Molecular simulations show that $n-\mathrm{C}_{6}$ fits comfortably in an AFX-type cage and is adsorbed to an appreciable extent under reaction

\section{Table 2}

Conversion of $n$-hexane $\left(n-\mathrm{C}_{6}\right)$ and $n$-hexadecane $\left(n-\mathrm{C}_{16}\right)$ obtained by processing either a pure or a mixed feed on AFX-type zeolites at $T=605 \mathrm{~K}$, hydrogen pressure $p_{\mathrm{H}_{2}}(\mathrm{kPa})$, hydrocarbon pressure $p_{\mathrm{HC}}(\mathrm{kPa})$, and hydrogen-tohydrocarbon ratios, $\mathrm{H}_{2} / \mathrm{HC}(\mathrm{mol} / \mathrm{mol})$ (data adapted from Santilli and Zones [30]). The loading, $L(\mathrm{mmol} / \mathrm{g})$ was obtained from molecular simulations on AFX-type silica, at reaction temperature and pressure, the acid site density, $\left[\mathrm{H}^{+}\right](\mathrm{mmol} / \mathrm{g})$, was calculated from the bulk aluminium-to-silicon ratio of the catalyst assuming that all aluminium is associated with an acid site. The apparent residence time, $\tau^{\prime}\left(\mathrm{s} \mathrm{m}_{\text {ads }}^{3} / \mathrm{m}_{\text {gas }}^{3}\right.$ ), was calculated using formula Eq. (1), with framework density $\rho=1463.7 \mathrm{~kg}$ ads $/ \mathrm{m}_{\text {ads }}^{3}$

\begin{tabular}{|c|c|c|c|c|}
\hline & \multirow{2}{*}{$\begin{array}{l}\text { Pure } \\
n-\mathrm{C}_{6}\end{array}$} & \multirow{2}{*}{$\begin{array}{l}\text { Pure } \\
n-\mathrm{C}_{16}\end{array}$} & \multicolumn{2}{|c|}{$n-\mathrm{C}_{6}$ and $n-\mathrm{C}_{16}$} \\
\hline & & & $n-\mathrm{C}_{6}$ part & $n-\mathrm{C}_{16}$ part \\
\hline$T(\mathrm{~K})$ & 605 & 605 & \multicolumn{2}{|c|}{605} \\
\hline$p_{\mathrm{H}_{2}}(\mathrm{kPa})$ & 8116 & 8203 & \multicolumn{2}{|c|}{8047} \\
\hline$p_{\mathrm{HC}}(\mathrm{kPa})$ & 158 & 71 & 157 & 70 \\
\hline WHSV ( $\left.\mathrm{kg}_{\text {ads }} /\left(\mathrm{kg}_{\text {gas }} \mathrm{h}\right)\right)$ & 1.32 & 1.55 & 1.32 & 1.55 \\
\hline$\tau^{\prime}\left(\mathrm{s} \mathrm{m}_{\mathrm{ads}}^{3} / \mathrm{m}_{\mathrm{gas}}^{3}\right)$ & 6.4 & 6.5 & 6.4 & 6.5 \\
\hline $\mathrm{H}_{2} / \mathrm{HC}(\mathrm{mol} / \mathrm{mol})$ & 51 & 115 & \multicolumn{2}{|c|}{36} \\
\hline $\mathrm{L}(\mathrm{mmol} / \mathrm{g})$ & 0.31 & $3.01 \times 10^{-6}$ & 0.30 & $1.50 \times 10^{-6}$ \\
\hline$\left[\mathrm{H}^{+}\right](\mathrm{mmol} / \mathrm{g})$ & 2 & 2 & \\
\hline Conversion (1) & 50 & 74 & 62 & $<1$ \\
\hline
\end{tabular}






(a)

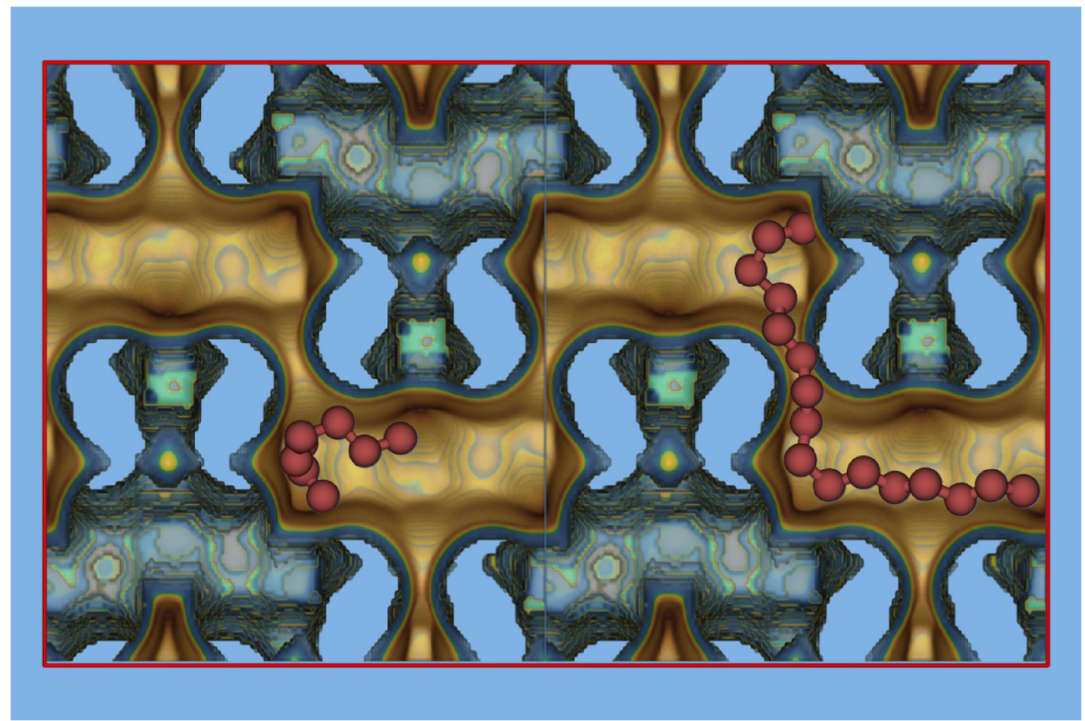

(b)

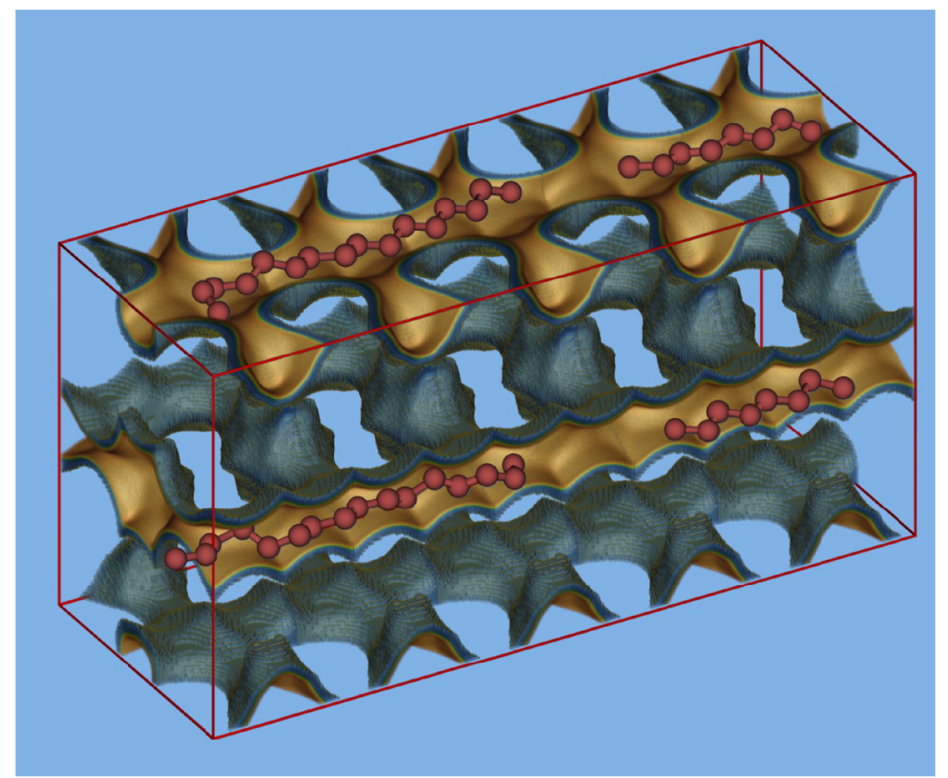

(c)

Fig. 3. Artist's impression of selected $n$-alkanes adsorbed in (a) the ERI-; (b) the AFX-; (c) the FER-type topology. At infinite dilution adsorption of $n$-alkanes longer than $n-\mathrm{C}_{5}$ remains confined to the larger, $0.48 \times 0.54 \mathrm{~nm}$ across FER-type channels [94]. 


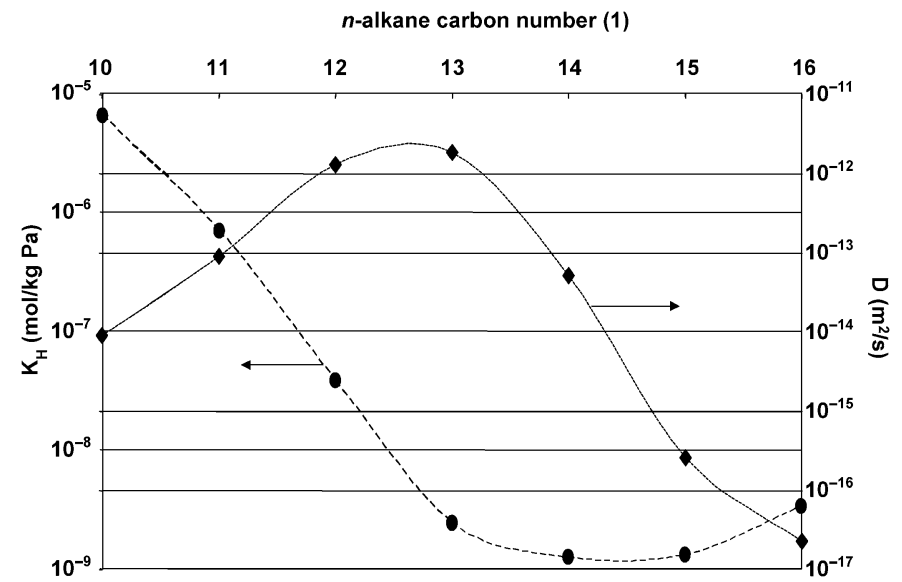

(a)



(b)

Fig. 4. (a) Variation of simulated diffusion coefficient $D\left(\mathrm{~m}^{2} / \mathrm{s}\right)(\diamond)$ and of simulated Henry coefficient $K_{\mathrm{H}}(\mathrm{mol} /(\mathrm{kg} \mathrm{K}))(\bullet)$ with $n$-alkane carbon number (1) (data adapted from Dubbeldam and Smit [59]); (b) variation of reported relative reaction rate constants $k^{\prime}\left(\mathrm{m}_{\text {gas }}^{3} /\left(\mathrm{m}_{\text {ads }}^{3} \mathrm{~s}\right)\right)(\square)$ (data adapted from Chen and Garwood [23,25]) and of simulated $K_{\mathrm{H}} \sqrt{D}$ $\left(\mathrm{mol} \mathrm{m} /\left(\mathrm{kg} \mathrm{Pa} \mathrm{s}^{1 / 2}\right)\right)(\diamond)$ with $n$-alkane carbon number. Both the $k^{\prime}$ and the $K_{\mathrm{H}} \sqrt{D}$ values were normalized to the values for $n$ - $\mathrm{C}_{11}$. Least squares regression lines are: $100 \times k^{\prime} / k_{n-\mathrm{C}_{11}}^{\prime}=1203 \mathrm{e}^{-0.23 \mathrm{CN}}$ and $100\left(K_{\mathrm{H}} \sqrt{D}\right) /$ $\left(K_{\mathrm{H} n-\mathrm{C}_{11}} \sqrt{D}_{n-\mathrm{C}_{11}}\right)=1.8 \mathrm{e}^{-2.0 \mathrm{CN}}$, with $\mathrm{CN}$ (1) the $n$-alkane carbon number.

conditions (Table 2). In marked contrast, $n-\mathrm{C}_{16}$ does not fit inside a single cage, so that part of its hydrocarbon chain has to protrude through an AFX-type window. As a result of the difference in fit, the adsorbed-phase $n-\mathrm{C}_{6}$ concentration approaches the saturation loading, whereas the $n-\mathrm{C}_{16}$ loading is in the Henry regime at reaction conditions (Table 2). When $n-\mathrm{C}_{6}$ and $n-\mathrm{C}_{16}$ are fed as a mixture, the huge excess of $n-\mathrm{C}_{6}$ in the adsorbed phase will simply block the access of $n-\mathrm{C}_{16}$ to any acid site at the interior crystal surface. Judging by the barrier to diffusion, $n-\mathrm{C}_{6}$ diffuses more rapidly than $n-\mathrm{C}_{16}$, further favoring the conversion of $n-\mathrm{C}_{6}$ instead of $n-\mathrm{C}_{16}$ if the $n-\mathrm{C}_{16}$ conversion is diffusion-limited. As with ERI-type zeolites, $n-\mathrm{C}_{16}$ conversion at exterior zeolite surfaces probably supplements $n-\mathrm{C}_{16}$ conversion at the interior AFX-type zeolite surface. But $n-\mathrm{C}_{16}$ adsorbing at the exterior surface is unlikely to compete with fully adsorbing $n-\mathrm{C}_{6}$ [82], and so the presence of $n-\mathrm{C}_{6}$ effectively impedes $n-\mathrm{C}_{16}$ adsorption and hydroconversion at both interior and exterior surfaces.
In contrast to the $n$-alkane conversion experiments on ERItype zeolites [23], the $n$-alkane conversion experiments with the AFX-type zeolites do not clearly show whether or not these latter zeolites are diffusion-limited. Our analysis predicts that AFX-type zeolites will exhibit a cage effect even in the absence of diffusion limitations.

\subsection{What singles out topologies likely to exhibit a cage effect?}

So far we have shown that a cage effect occurs when $n$ alkanes too long to fit inside a single cage experience repulsive van der Waals interactions at the windows connecting the cages. These repulsive van der Waals interactions increase the Gibbs free energy of adsorption of such a long molecule relative to that of a short molecule and thereby stymie its adsorption and conversion. One way to assess whether the windows of a particular topology exert repulsive van der Waals interactions is to evaluate the Gibbs free energy of adsorption of a long molecule like $n$-pentacosane $\left(n-\mathrm{C}_{25}\right)$ as a function of window size. The Gibbs free energy consists of an enthalpy component and an entropy component. The enthalpy indicates whether the forces between adsorbent and adsorbate are attractive or repulsive; the entropy reflects the loss in mobility on adsorption. A closer look at the changes of both enthalpy and entropy with window size provides some insight. The change in enthalpy with window size approaches a Lennard-Jones potential. The FER- and TON-type windows are at the bottom of the potential well, that is, where increasingly more repulsive van der Waals interactions start to outweigh the attractive van der Waals interactions (Fig. 5a). The slightly smaller EUO- and MTT-type windows are the first topologies on the upward branch of the LennardJones potential that is dominated by repulsive interactions. The change in adsorption entropy with window size approaches an exponential decay, but becomes erratic when the window size becomes so small that repulsive interactions dominate (Fig. 5b). The resultant change in Gibbs free energy of adsorption with decreasing window size resembles another Lennard-Jones potential (Fig. 5c). Initially, the Gibbs free energy decreases with decreasing window size, because the decrease in adsorption enthalpy outweighs the decrease in adsorption entropy. The MTW- and GON-type windows are at the bottom of the curve, representing the point where the increasingly lower mobility (decreasing entropy) starts to outweigh the increasingly more attractive van der Waals interactions (decreasing enthalpy). At the EUO- and MTT-type windows, the Gibbs free energy increases dramatically, because the van der Waals interactions have switched from attractive to repulsive, so that now increasing enthalpy and decreasing entropy cooperatively increase the Gibbs free energy with decreasing pore size.

Although an analysis of the effect of window size on adsorption thermodynamics is insightful, clearly cage size also needs to be taken into consideration. The cage size determines the number of windows through which the adsorbed $n-\mathrm{C}_{25}$ has to squeeze. One can evaluate the combined effect of the window and cage size on the adsorption properties by studying adsorption enthalpy as a function of adsorption entropy. Naturally, 


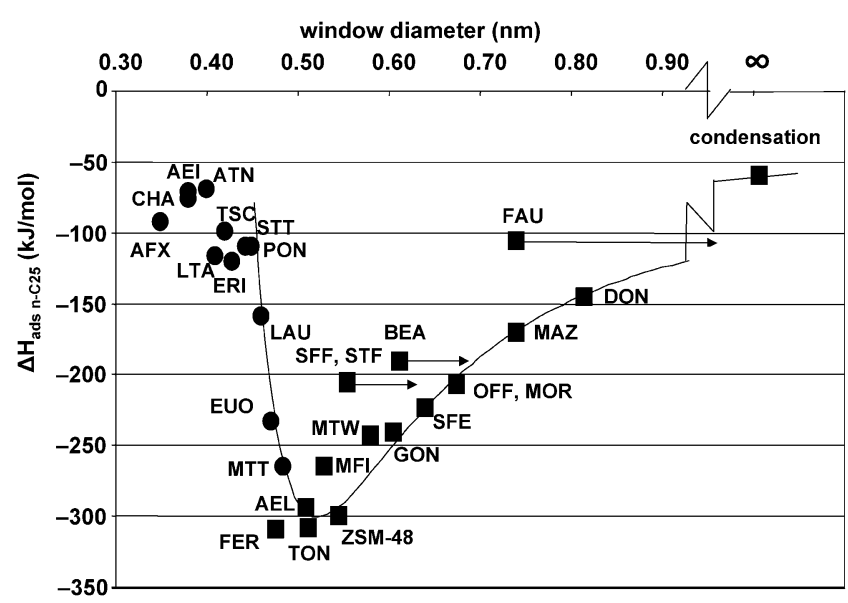

(a)



(b)

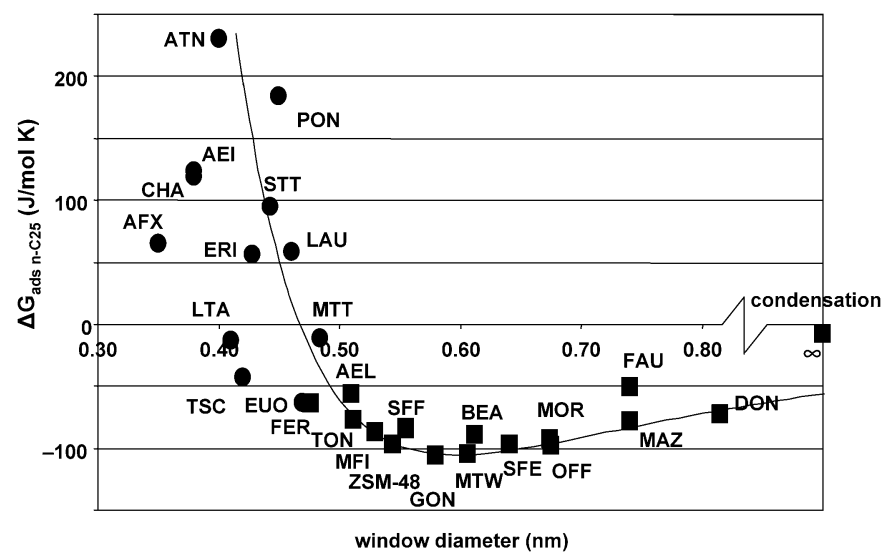

(c)

Fig. 5. Variation with window size of (a) simulated adsorption enthalpy $\Delta H_{\text {ads } n}-C_{25}(\mathrm{~kJ} / \mathrm{mol})$, (b) adsorption entropy $\Delta S_{\text {ads } n-\mathrm{C}_{25}}(\mathrm{~kJ} / \mathrm{mol})$, and (c) Gibbs free energy of adsorption of $n$-pentacosane, $\Delta G_{\text {ads } n}-\mathrm{C}_{25}(\mathrm{~kJ} / \mathrm{mol})$, at $605 \mathrm{~K}$. The Lennard-Jones potential obtained by plotting enthalpy as function of window size indicates a switch from predominantly attractive (凹) to predominantly repulsive (@) van der Waals interactions at around the $0.48 \mathrm{~nm}$ pore diameter of MTT-type zeolites. The lines to guide the eye in Fig. 5 represent Lennard-Jones-like fits of the data for topologies with small cages: (a) $\Delta H=520 \times\left[(0.44 / d)^{12}-(0.44 / d)^{3.5}\right]-79$; (b) $\Delta S=-421 \times(0.44 / d)^{3.5}-83$; (c) $\Delta G=750 \times\left[(0.47 / d)^{5}-(0.47 / d)^{3.5}\right]$ -8.0 . Clearly window size poorly characterizes the adsorption properties of pores with sizeable cages such as TSC-, FAU-, LTA-, BEA-, STF-, and SFF-type zeolites, for these do not fit well with the suggested correlations.

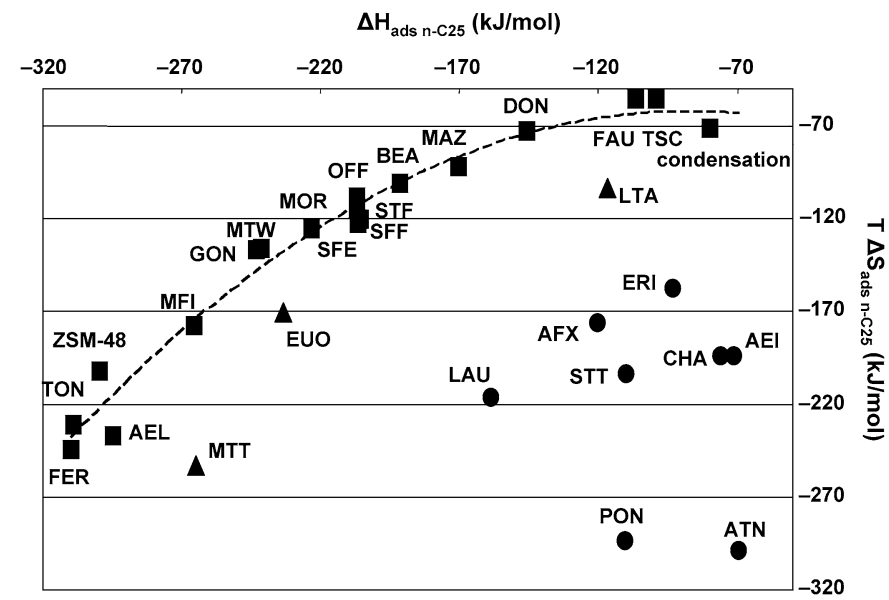

Fig. 6. Evaluation of the simulated adsorption enthalpy, $\Delta H_{\text {ads } n-C_{25}}(\mathrm{~kJ} / \mathrm{mol})$, as a function of the product of the temperature $(T=605 \mathrm{~K})$ and the simulated adsorption entropy, $T \Delta S_{\text {ads } n-\mathrm{C}_{25}}(\mathrm{~kJ} / \mathrm{mol})$ of $n$-pentacosane affords discrimination between topologies with attractive (ם), slightly repulsive $(\boldsymbol{\Lambda})$, and strongly repulsive (\) van der Waals interactions. The enthalpy and entropy for $n$-pentacosane condensation were extrapolated from experimental data reported by Chickos [79]. For 97\%, the enthalpy $(\mathrm{kJ} / \mathrm{mol})$ and temperature $\times$ entropy $(\mathrm{kJ} / \mathrm{mol})$ of topologies with attractive van der Waals interactions obey the relationship $T \Delta S_{\text {ads } n-\mathrm{C}_{25}}=$ $-3.6 \times 10^{-3}\left(\Delta H_{\text {ads } n}-\mathrm{C}_{25}\right)^{2}-0.62 \Delta H_{\text {ads } n}-\mathrm{C}_{25}-89.6$ (curved line in figure). Interestingly, this second-order relationship is in stark contrast with the usually reported linear (compensation) relation between $\Delta H_{\text {ads }}$ and $T \Delta S_{\text {ads }}[21,40]$.

a consideration of the complete pore topology yields more robust correlations than one limited only to window size.

With decreasing pore size (from "condensation" to FER), attractive van der Waals interactions simultaneously constrain and stabilize adsorbed $n-\mathrm{C}_{25}$ (Fig. 6; Table 3); that is, they decrease the adsorption entropy and enthalpy, respectively. Clearly, the pores have a greater impact on the adsorption entropy than on the adsorption enthalpy, because the adsorption entropy is proportional to the square of the adsorption enthalpy and so decreases more rapidly (as represented by the curve in Fig. 6).

When the pores contain windows narrow enough to exert repulsive van der Waals interactions on $n-\mathrm{C}_{25}$, the quadratic relationship between adsorption entropy and enthalpy breaks down and the Gibbs free energy of adsorption increases (Fig. 6; Table 3). Repulsive van der Waals interactions at narrow windows destabilize adsorbed $n-\mathrm{C}_{25}$ but constrain $n-\mathrm{C}_{25}$ just as effectively as attractive van der Waals interactions; that is, they raise the adsorption enthalpy without affecting the adsorption entropy. Thus, one could distinguish between (i) attractive, (ii) weakly repulsive, and (iii) strongly repulsive van der Waals interactions. The distinction between weakly repulsive and strongly repulsive van der Waals interactions is that only the latter raise the enthalpy sufficiently to result in a positive Gibbs free energy of adsorption (Table 3). Each of these three types of van der Waals interactions has a different propensity to induce a cage effect.

Topologies with attractive van der Waals interactions should not exhibit a cage effect, because the adsorption constant increases exponentially with $n$-alkane length (Fig. 7a), whereas the diffusion constant tends to decrease only quadratically with 
Table 3

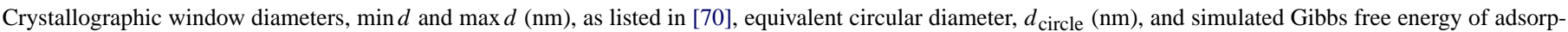

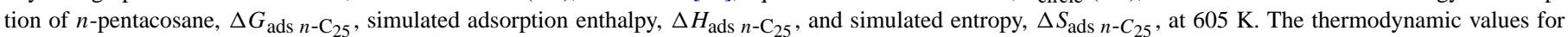
adsorption in infinitely large pores $(d=\infty \mathrm{nm})$ at $605 \mathrm{~K}$ are derived from the experimental values for condensation as reported by Chickos [79]

\begin{tabular}{|c|c|c|c|c|c|c|c|}
\hline $\begin{array}{l}\text { Van der Waals } \\
\text { interactions type }\end{array}$ & $\begin{array}{l}\text { Structure } \\
\text { type }\end{array}$ & $\begin{array}{l}\operatorname{Min} d \\
(\mathrm{~nm})\end{array}$ & $\begin{array}{l}\operatorname{Max} d \\
(\mathrm{~nm})\end{array}$ & $\begin{array}{l}d_{\text {circle }} \\
(\mathrm{nm})\end{array}$ & $\begin{array}{l}\Delta G_{\text {ads } n-\mathrm{C}_{25}} \\
(\mathrm{~kJ} / \mathrm{mol})\end{array}$ & $\begin{array}{l}\Delta H_{\mathrm{ads} n}-\mathrm{C}_{25} \\
(\mathrm{~kJ} / \mathrm{mol})\end{array}$ & $\begin{array}{l}\Delta S_{\text {ads } n-\mathrm{C}_{25}} \\
(\mathrm{~J} / \mathrm{mol} \mathrm{K})\end{array}$ \\
\hline \multirow[t]{18}{*}{ Attractive } & - & $\infty$ & $\infty$ & $\infty$ & -8.1 & -60 & -86 \\
\hline & TSC & 0.42 & 0.42 & 0.42 & -43.1 & -99 & -92 \\
\hline & FAU & 0.74 & 0.74 & 0.74 & -50.9 & -113 & -102 \\
\hline & DON & 0.81 & 0.82 & 0.81 & -71.9 & -121 & -82 \\
\hline & MAZ & 0.74 & 0.74 & 0.74 & -78.7 & -171 & -153 \\
\hline & BEA & 0.67 & 0.56 & 0.61 & -90.1 & -173 & -138 \\
\hline & MOR & 0.65 & 0.70 & 0.67 & -92.8 & -186 & -154 \\
\hline & GON & 0.54 & 0.68 & 0.61 & -104.1 & -194 & -149 \\
\hline & STF & 0.54 & 0.57 & 0.55 & -84.7 & -205 & -199 \\
\hline & SFF & 0.54 & 0.57 & 0.55 & -83.4 & -206 & -203 \\
\hline & OFF & 0.67 & 0.68 & 0.67 & -98.3 & -207 & -180 \\
\hline & SFE & 0.54 & 0.76 & 0.64 & -97.0 & -223 & -209 \\
\hline & MTW & 0.56 & 0.60 & 0.58 & -105.8 & -243 & -226 \\
\hline & MFI & 0.51 & 0.55 & 0.53 & -87.1 & -265 & -295 \\
\hline & AEL & 0.40 & 0.65 & 0.51 & -58.5 & -284 & -373 \\
\hline & ZSM-48 & 0.53 & 0.56 & 0.54 & -92.4 & -292 & -330 \\
\hline & TON & 0.46 & 0.57 & 0.51 & -77.1 & -309 & -383 \\
\hline & FER & 0.42 & 0.54 & 0.48 & -64.6 & -310 & -405 \\
\hline \multirow[t]{3}{*}{ Weakly repulsive } & LTA & 0.41 & 0.41 & 0.41 & -13.1 & -117 & -171 \\
\hline & EUO & 0.41 & 0.54 & 0.47 & -63.1 & -234 & -282 \\
\hline & MTT & 0.45 & 0.52 & 0.48 & -3.8 & -243 & -396 \\
\hline \multirow[t]{8}{*}{ Strongly repulsive } & AFX & 0.34 & 0.36 & 0.35 & 64.7 & -92.9 & -261 \\
\hline & AEI & 0.38 & 0.38 & 0.38 & 123 & -71.2 & -321 \\
\hline & $\mathrm{CHA}$ & 0.38 & 0.38 & 0.38 & 119 & -75.7 & -322 \\
\hline & ATN & 0.40 & 0.40 & 0.40 & 230 & -69.5 & -495 \\
\hline & ERI & 0.36 & 0.51 & 0.43 & 55.9 & -120 & -291 \\
\hline & STT & 0.37 & 0.53 & 0.44 & 94.1 & -110 & -337 \\
\hline & PON & 0.44 & 0.46 & 0.45 & 184 & -110 & -486 \\
\hline & LAU & 0.40 & 0.53 & 0.46 & 58.3 & -159 & -359 \\
\hline
\end{tabular}

$n$-alkane length $[6,83,84]$. Accordingly, the variation in adsorption constant is likely to dominate the conversion rate (both $K_{\mathrm{H}}$ and $K_{\mathrm{H}} \sqrt{D}$ ), which favors conversion of the longer $n$-alkanes.

Topologies with weakly repulsive van der Waals interactions can exhibit a cage effect, because the adsorption constant does not vary as strongly with $n$-alkane length as with either attractive or strongly repulsive van der Waals interactions (Fig. 7b). Accordingly, the variation in diffusion constant with $n$-alkane length is likely to contribute significantly to the absence or presence of a cage effect.

Topologies with strongly repulsive van der Waals interactions should exhibit a cage effect, because their adsorption constant decreases (in a nonmonotonic fashion) significantly with $n$-alkane length (Fig. 7c). Even though strongly repulsive van der Waals interactions appear to induce relatively large variations in diffusion constants [50,59,71-73], the likely net result $\left(K_{\mathrm{H}} \sqrt{D}\right)$ is that these topologies will tend to favor conversion of the shorter $n$-alkanes.

Surprisingly, it has repeatedly been reported that a FER-type zeolite [29,31] (which, according to our analysis, should exert attractive van der Waals interactions) exhibits a cage effect. This is in direct contradiction to our analysis and merits closer scrutiny to evaluate if and how the above analysis needs to be refined.

\subsection{Adsorption, diffusion, and coke can combine to yield a cage effect for a FER-type zeolite}

Our analysis of zeolite topologies indicates that FER-type zeolites exhibit attractive van der Waals interactions and thus should not exhibit a cage effect. In agreement with our assessment, FER-type zeolites selectively remove long-chain rather than short-chain $n$-alkanes from complex industrial feeds at hydroprocessing conditions $[85,86]$.

Inconsistent with our assessment, FER-type zeolites can reportedly exhibit a cage effect at the very conditions used for the selective hydroconversion of long-chain $n$-alkanes [29,85]. A possible cause of this surprising selectivity inversion could be contamination with MOR-type zeolite [29]. Intergrowths between FER-type and MOR-type zeolites drastically reduce the pore size and diffusion rates in these FER-type zeolites [87-89]. Such a pore size reduction could very well cause the anomalous cage effect that these peculiar FER-type zeolite samples exhibit at conditions under which other FER-type zeolites remove long-chain instead of short-chain $n$-alkanes.

A second report on a cage effect with FER-type zeolites uses conditions very different from those used in hydroprocessing [31]: Instead of using steady-state conditions (many hours on stream) in the presence of hydrogen at $\sim 605 \mathrm{~K}$ [85], it uses 


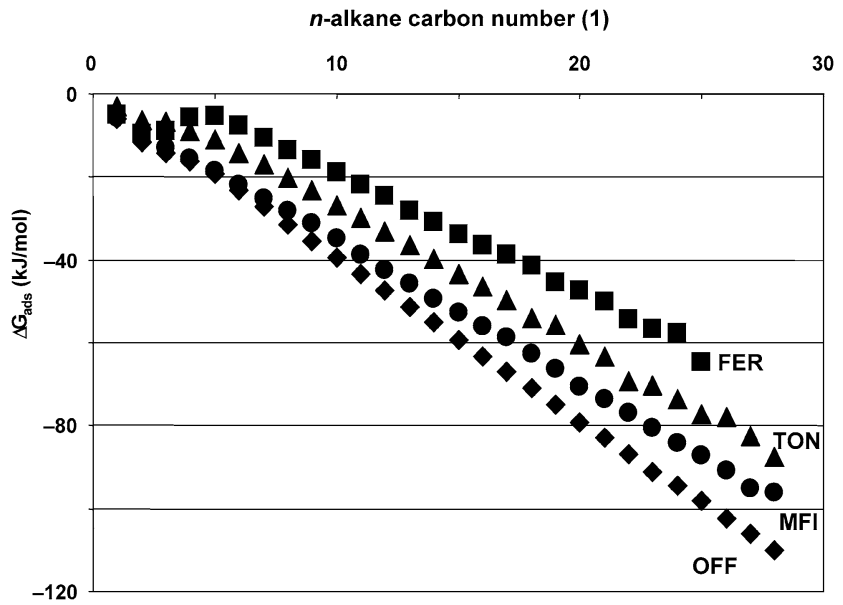

(a)

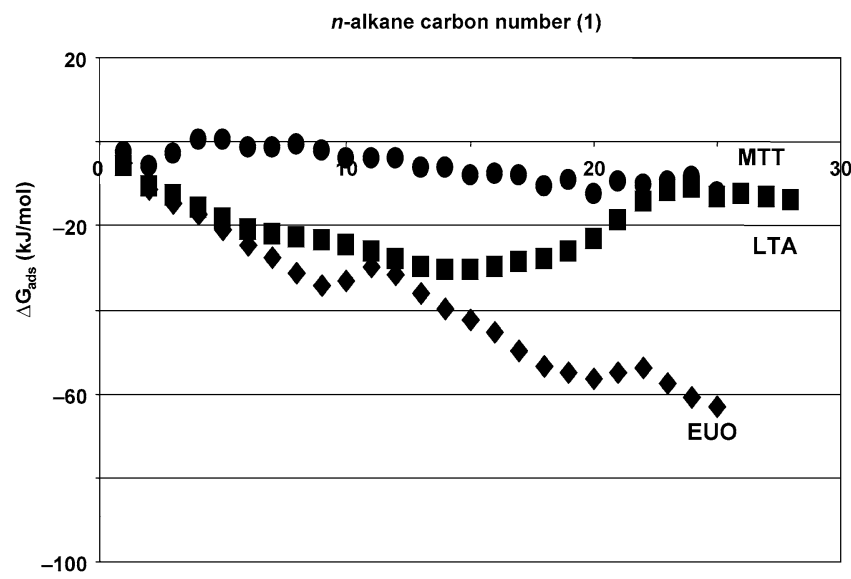

(b)



n-alkane carbon number (1)

(c)

Fig. 7. Variation of the simulated Gibbs free energy of adsorption, $\Delta G_{\text {ads }}$ $(\mathrm{kJ} / \mathrm{mol})$, at $605 \mathrm{~K}$ as a function of carbon number, $\mathrm{CN}$ (1), for (a) OFF- ( $)$ ),

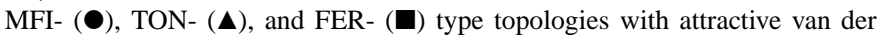
Waals interactions, for (b) EUO- $(\bullet)$, LTA- $(\boldsymbol{\square})$, and MTT- $(\bullet)$ type topologies with moderately repulsive van der Waals interactions and for (c) ERI- ( $\bullet$ ),

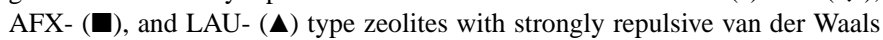
interactions.

transient conditions in the absence of hydrogen at $773 \mathrm{~K}$. At these conditions, the activity of FER-type zeolites declines significantly due to pore blockage by consecutive reaction products [90]. Because the cage effect study does not include any in- formation on the activity decline [31], we use comparative data from an extensive kinetic study on MFI-type zeolites $[16,17]$ to gain a better perspective of the catalytic cracking conditions (Table 4).

The cage effect study (on FER) [31] and the kinetic study (on MFI) $[16,17]$ agree on the intrinsic cracking rate constant for $n-\mathrm{C}_{8}$, but not on that for $n-\mathrm{C}_{16}$ (Table 4). According to the kinetic study $[16,17]$, the intrinsic cracking rate of $n-\mathrm{C}_{16}$ on MFI-type zeolites is nearly twice that of $n-\mathrm{C}_{8}$ (Fig. 8; Table 5). At the conditions used by the cage effect study, such a cracking rate constant would correspond to $99.97 \% n-\mathrm{C}_{16}$ conversion, not to the reported $79 \%$ conversion (Table 4 ). This suggests that the cracking conditions for $n-\mathrm{C}_{16}$ used in the cage effect study are too severe (i.e., too long a contact time for the high acid site density of the FER-type zeolite) to measure true kinetics, and that the observed $n-\mathrm{C}_{16}$ conversion is seriously restricted through pore blockage by consecutive reaction products. Usually pore blockage favors conversion of the fastest-diffusing species.

Molecular simulations indicate that $n-\mathrm{C}_{8}$ diffuses faster than $n-\mathrm{C}_{16}$ (Table 4 ), so that $n-\mathrm{C}_{8}$ will beat the trailing $n-\mathrm{C}_{16}$ to adsorption at the acid sites. The decrease of the effective pore diameter through coke make [91] is likely to enhance the competitive advantage of the more agile $n-\mathrm{C}_{8}$ over the more sluggish $n-\mathrm{C}_{16}$. The net result is that more $n-\mathrm{C}_{8}$ than $n-\mathrm{C}_{16}$ is converted by the time the feed has left a deactivated, clogged FER-type zeolite behind inside the reactor.

The coke-enhanced preference for converting the fastest diffusing $n$-alkane is probably only part of the reason for the deleterious effect of $n-\mathrm{C}_{8}$ on $n-\mathrm{C}_{16}$ conversion on this FER-type zeolite. As with the cage effect reported for ERI- and AFXtype zeolites, there is an adsorption aspect in addition to this diffusion aspect.

At low (hydroprocessing) temperatures, FER-type zeolites should not exhibit a cage effect, because the enthalpy term dominates the Gibbs free energy of adsorption, favoring adsorption of the longer $n$-alkanes. At extremely high temperatures, FER-type zeolites will exhibit a cage effect, because the entropy term dominates the Gibbs free energy of adsorption, favoring the adsorption of the smaller $n$-alkanes (Fig. 9). At intermediate temperatures, the enthalpy and entropy terms are of similar magnitude, rendering the Gibbs free energy invariant to the $n$-alkane chain length (Fig. 9). The catalytic cracking experiments on the FER-type zeolite were performed in this intermediate temperature range, in which the Gibbs free energy of adsorption for MFI-type zeolites still decreases with $n$-alkane chain length (Fig. 9) due to the higher (less negative) adsorption entropy exhibited by MFI-type zeolites (Fig. 6; Table 3). Accordingly, FER-type zeolites are indifferent to the adsorption of either $n-\mathrm{C}_{8}$ or $n-\mathrm{C}_{16}$, whereas MFI-type zeolites maintain their strong preference for $n-\mathrm{C}_{16}$ at the catalytic cracking temperature (Figs. 8 and 9). When the impact of adsorption thermodynamics on the preferential adsorption of short-chain or long-chain $n$-alkanes is diminished, the impact of adsorption kinetics increases proportionally.

Clearly, molecular simulations can elucidate aspects of the cage effect reportedly exhibited by FER-type zeolites in cat- 
Table 4

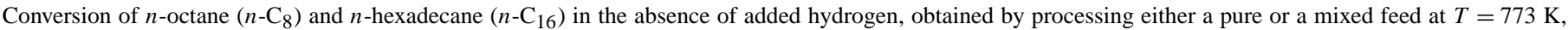

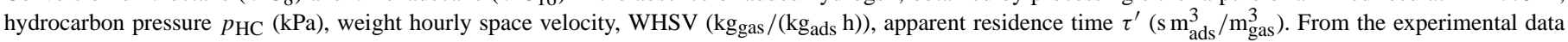

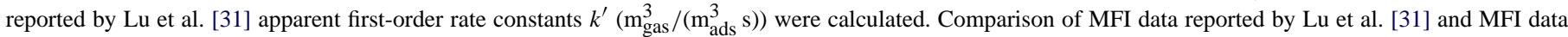

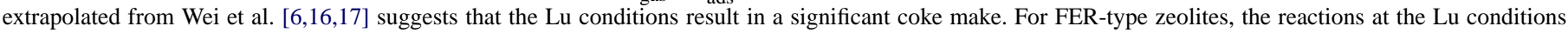

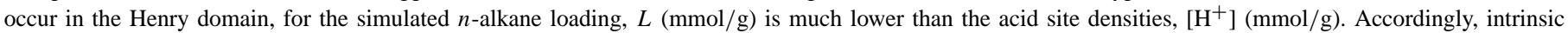

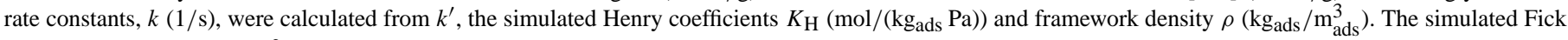
diffusion coefficients, $D\left(\mathrm{~m}^{2} / \mathrm{s}\right)$, suggest that the reactions are not diffusion limited (Thiele modulus $\left.\Phi<2\right)$ at reasonable crystal sizes $(\delta<5 \mu \mathrm{m})$

\begin{tabular}{|c|c|c|c|c|c|c|c|c|c|c|}
\hline & \multicolumn{10}{|l|}{ Data source } \\
\hline & \multirow{2}{*}{$\begin{array}{l}31] \\
n-\mathrm{C}_{8}\end{array}$} & \multirow{2}{*}{$\begin{array}{l}{[31]} \\
n-\mathrm{C}_{16}\end{array}$} & \multicolumn{2}{|c|}{ Mixture [31] } & \multirow{2}{*}{$\begin{array}{l}{[16,17]} \\
n-\mathrm{C}_{8}\end{array}$} & \multirow{2}{*}{$\begin{array}{l}{[16,17]} \\
n-\mathrm{C}_{16}\end{array}$} & \multirow{2}{*}{$\begin{array}{l}{[31]} \\
n-\mathrm{C}_{8}\end{array}$} & \multirow{2}{*}{$\begin{array}{l}{[31]} \\
n-\mathrm{C}_{16} \\
\end{array}$} & \multicolumn{2}{|c|}{ Mixture [31] } \\
\hline & & & $n-\mathrm{C}_{8}$ & $n-\mathrm{C}_{16}$ & & & & & $n-\mathrm{C}_{8}$ & $n-\mathrm{C}_{16}$ \\
\hline Topology & MFI & MFI & \multicolumn{2}{|c|}{ MFI } & MFI & MFI & FER & FER & \multicolumn{2}{|c|}{ FER } \\
\hline$\rho\left(\mathrm{kg}_{\mathrm{ads}} / \mathrm{m}_{\mathrm{ads}}^{3}\right)$ & 1796 & 1796 & \multicolumn{2}{|c|}{1796} & 1796 & 1796 & 1772 & 1772 & \multicolumn{2}{|c|}{1772} \\
\hline$T(\mathrm{~K})$ & 773 & 773 & \multicolumn{2}{|c|}{773} & 773 & 773 & 773 & 773 & \multicolumn{2}{|c|}{773} \\
\hline WHSV $(\mathrm{kg} /(\mathrm{kg} \mathrm{h}))$ & 51 & 51 & 24 & 27 & - & - & 51 & 51 & 24 & 27 \\
\hline$p_{\mathrm{HC}}(\mathrm{kPa})$ & 101 & 101 & 65.1 & 36.2 & - & - & 101 & 101 & 65.1 & 36.2 \\
\hline$\tau^{\prime}\left(\mathrm{s} \mathrm{m}_{\mathrm{ads}}^{3} / \mathrm{m}_{\mathrm{gas}}^{3}\right)$ & 0.08 & 0.17 & \multicolumn{2}{|c|}{0.11} & - & - & 0.09 & 0.17 & \multicolumn{2}{|c|}{0.12} \\
\hline Conversion (1) & 25.8 & 79 & 27 & 78.5 & $29.5^{\mathrm{a}}$ & $99.97^{\mathrm{a}}$ & 27.6 & 67.1 & 28.3 & 14.3 \\
\hline$k^{\prime}\left(\mathrm{m}_{\mathrm{gas}}^{3} /\left(\mathrm{m}_{\mathrm{ads}}^{3} \mathrm{~s}\right)\right)$ & 3.5 & 9.3 & 2.7 & 13.4 & $3.9^{\mathrm{a}}$ & $45.5^{\mathrm{a}}$ & 3.8 & 6.5 & 2.9 & 1.3 \\
\hline$L(\mathrm{mmol} / \mathrm{g})$ & - & - & - & - & - & - & $9.7 \times 10^{-4}$ & $7.2 \times 10^{-4}$ & $9.7 \times 10^{-4}$ & $2.1 \times 10^{-4}$ \\
\hline$\left[\mathrm{H}^{+}\right](\mathrm{mmol} / \mathrm{g})$ & $<0.16$ & $<0.16$ & $<0.16$ & $<0.16$ & 0.17 & 0.17 & 1.9 & 1.9 & 1.9 & 1.9 \\
\hline$K_{\mathrm{H}}(\mathrm{mol} /(\mathrm{kg} \mathrm{Pa}))$ & $2.24 \times 10^{-7}$ & $1.53 \times 10^{-6}$ & $2.24 \times 10^{-7}$ & $1.53 \times 10^{-6}$ & $2.24 \times 10^{-7}$ & $1.53 \times 10^{-6}$ & $1.29 \times 10^{-8}$ & $1.02 \times 10^{-8}$ & $1.29 \times 10^{-8}$ & $1.02 \times 10^{-8}$ \\
\hline$k(1 / \mathrm{s})$ & 1.36 & 0.52 & 1.06 & 0.76 & $1.50^{\mathrm{b}}$ & $2.57^{\mathrm{b}}$ & 25.6 & 56.1 & 19.5 & 11.4 \\
\hline$D\left(\mathrm{~m}^{2} / \mathrm{s}\right)$ & - & - & - & - & - & - & $3.1 \times 10^{-8}$ & $2.0 \times 10^{-8}$ & - & - \\
\hline
\end{tabular}

a Calculated from the intrinsic reaction rate constants of [16,17] with the experimental conditions of [31].

b Obtained through extrapolation to slightly higher temperatures than employed experimentally.

Table 5

The apparent preexponential factor, $k_{0} K_{\mathrm{H} 0}(\mathrm{~mol} /(\mathrm{kg} \mathrm{Pas}))$, and apparent activation energy $E_{\text {act app }}(\mathrm{kJ} / \mathrm{mol})$ for the cracking of $n$-alkanes with various carbon numbers, $\mathrm{CN}$ (1), on MFI-type zeolites in the absence of added hydrogen as reported by Wei et al. [6,16,17] as described by $k K_{\mathrm{H}}=k_{0} K_{\mathrm{H} 0}$ $\mathrm{e}^{\left(-E_{\text {act app }} / R T\right)}$ and depicted in Fig. 8a; the corresponding preexponential Henry coefficient, $K_{\mathrm{H} 0}(\mathrm{~mol} /(\mathrm{kg} \mathrm{Pa}))$ and adsorption enthalpy, $\Delta H(\mathrm{~kJ} / \mathrm{mol})$, in $K_{\mathrm{H}}=K_{\mathrm{H} 0} \mathrm{e}^{(-\Delta H / R T)}$ as obtained through molecular simulations (Fig. 8b); and the resultant intrinsic preexponential factor $k_{0}(1 / \mathrm{s})$ and intrinsic activation energy $E_{\text {act }}(\mathrm{kJ} / \mathrm{mol})$ in $k=k_{0} \mathrm{e}^{\left(-E_{\text {act }} / R T\right)}$ (Fig. 8c). In these correlations $R$ is the gas constant $(8.3144 \mathrm{~J} /(\mathrm{mol} \mathrm{K}))$ and $T(\mathrm{~K})$ is the absolute temperature

\begin{tabular}{|c|c|c|c|c|c|c|}
\hline $\begin{array}{l}\mathrm{CN} \\
(1) \\
\end{array}$ & $\begin{array}{l}k_{0} K_{\mathrm{H} 0} \\
(\mathrm{~mol} /(\mathrm{kg} \mathrm{Pa} \mathrm{s}))\end{array}$ & $\begin{array}{l}E_{\text {act app }} \\
(\mathrm{kJ} / \mathrm{mol})\end{array}$ & $\begin{array}{l}K_{\mathrm{H} 0} \\
(\mathrm{~mol} /(\mathrm{kg} \mathrm{Pa}))\end{array}$ & $\begin{array}{l}\Delta H \\
(\mathrm{~kJ} / \mathrm{mol})\end{array}$ & $\begin{array}{l}k_{0} \\
(1 / \mathrm{s})\end{array}$ & $\begin{array}{l}E_{\text {act }} \\
(\mathrm{kJ} / \mathrm{mol})\end{array}$ \\
\hline 8 & $1.16 \mathrm{E}-01$ & 80 & $5.33 \mathrm{E}-13$ & -84.1 & $2.18 \mathrm{E}+11$ & 164 \\
\hline 10 & $2.84 \mathrm{E}-02$ & 65 & $4.08 \mathrm{E}-14$ & -102.8 & $6.97 \mathrm{E}+11$ & 168 \\
\hline 12 & $2.42 \mathrm{E}-03$ & 44 & $4.17 \mathrm{E}-15$ & -120.9 & $5.80 \mathrm{E}+11$ & 165 \\
\hline 14 & $3.67 \mathrm{E}-05$ & 15 & $3.90 \mathrm{E}-16$ & -139.0 & $9.40 \mathrm{E}+10$ & 154 \\
\hline 16 & $1.53 \mathrm{E}-06$ & -7 & $2.31 \mathrm{E}-17$ & -159.2 & $6.64 \mathrm{E}+10$ & 152 \\
\hline 18 & $9.61 \mathrm{E}-08$ & -27 & $1.51 \mathrm{E}-18$ & -178.9 & $6.38 \mathrm{E}+10$ & 152 \\
\hline 20 & $2.75 \mathrm{E}-08$ & -39 & $1.13 \mathrm{E}-19$ & -198.9 & $2.43 \mathrm{E}+11$ & 160 \\
\hline
\end{tabular}

alytic cracking. However, the intrusion of coke formation and its effect on the adsorption and diffusion properties of the resultant catalyst limits its utility. A more extensive kinetic study would be of benefit.

\section{Conclusions}

A cage effect can be defined as a form of reactant shape selectivity observed when a zeolite preferentially converts a short-chain instead of a long-chain $n$-alkane at a low pressure and loading. An analysis of the cage effects exhibited by ERItype and AFX-type zeolites [22-28,30] shows that the adsorp- tion thermodynamics of the $n$-alkanes is at least as important a constituent of the cage effect as the $n$-alkane diffusion rate. This highlights a shortcoming in the traditional view of reactant shape selectivity as the unambiguous effect of a zeolite topology on the preferential conversion of the reactant that adsorbs most rapidly in diffusion-limited reactions. Such a definition needs to be complemented by the unambiguous effect of a zeolite topology on the reactant that adsorbs the most. Similarly, recent papers have reported that the traditional definition of product shape selectivity as the preferential production of the product that desorbs most rapidly needs to be complemented by the unambiguous effect of a zeolite topology on the product that desorbs the most $[92,93]$.

An analysis of the effects of zeolite topology on the adsorption properties of $n$-alkanes affords categorization of the topologies according to their propensity to exhibit a cage effect at typical hydroprocessing conditions. Topologies most prone to exhibiting a cage effect contain a high density of narrow constrictions ("windows") that strongly repel long $n$-alkanes, resulting in a positive Gibbs free energy of long-chain $n$-alkane adsorption. Topologies least prone to exhibiting a cage effect contain spacious voids that attract long $n$-alkanes, resulting in a negative Gibbs free energy of long-chain $n$-alkane adsorption.

In the absence of contamination [29], FER-type zeolites should not exhibit a cage effect at typical hydroprocessing conditions, because they exhibit a negative Gibbs free energy of adsorption for long-chain $n$-alkanes. At temperatures higher than those typically used in hydroprocessing, FER-type zeolites change category from topologies with a negative Gibbs free energy of adsorption for long-chain $n$-alkanes to those with a positive Gibbs free energy of adsorption for long-chain $n$-al- 


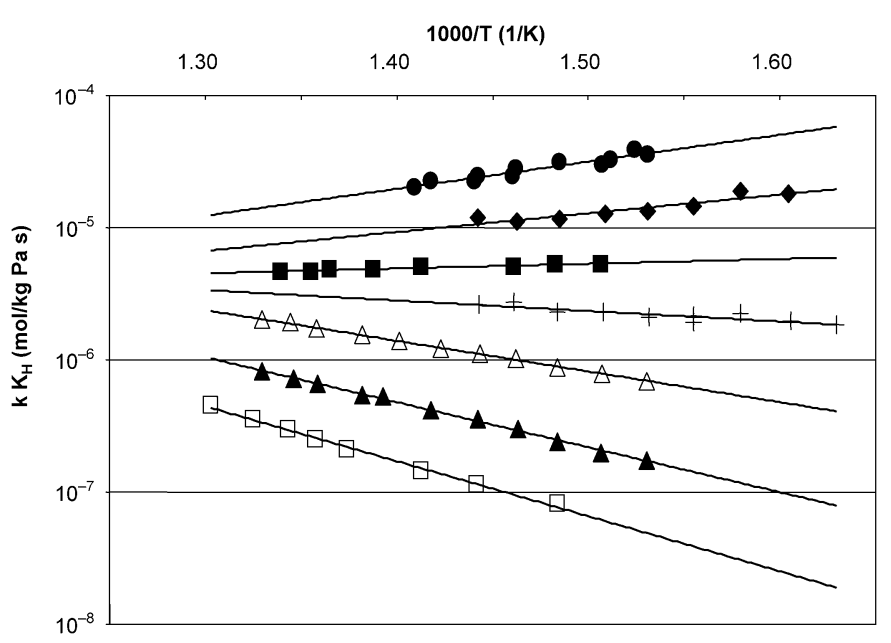

(a)

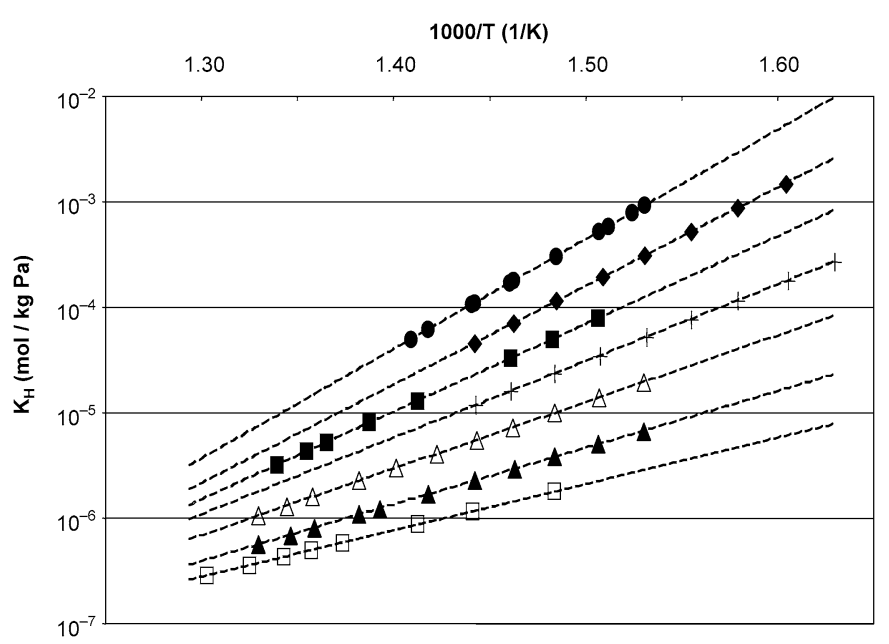

(b)

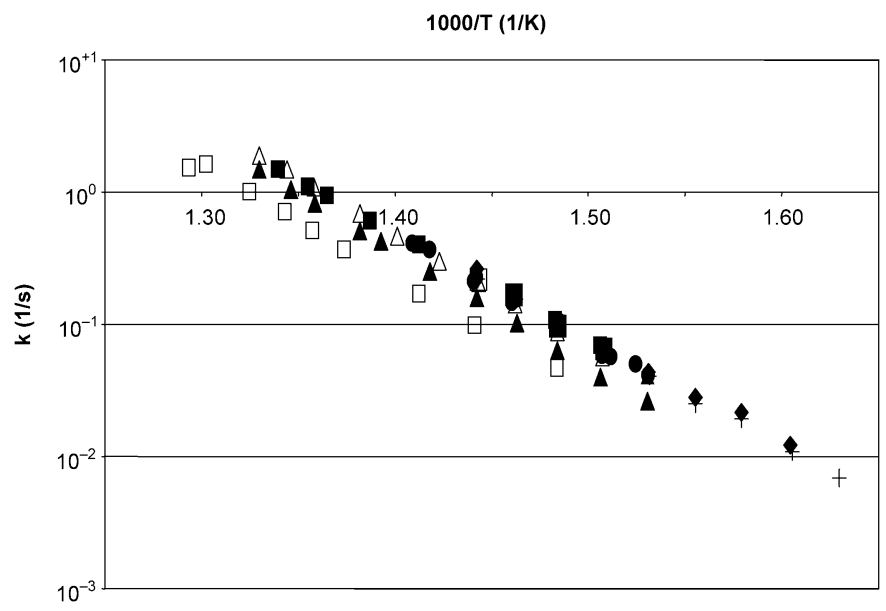

(c)

Fig. 8. (a) Product of intrinsic reaction rate constant, $k(1 / \mathrm{s})$, and Henry coefficient, $K_{\mathrm{H}}(\mathrm{mol} /(\mathrm{kg} \mathrm{Pa}))$ observed for cracking $n$-alkanes on MFI-type zeolites at various reciprocal temperatures $1 / T(1 / K)$ in the absence of added hydrogen (adapted from Wei et al. [6,16,17]); (b) Henry coefficient, $K_{\mathrm{H}}$, in MFI-type silica simulated for $n$-alkanes at these reciprocal temperatures, (c) intrinsic reaction rate constants, $k$, as calculated from measured $k K_{\mathrm{H}}$ (a) and simulated $K_{\mathrm{H}}$ (b). In all figures the legend is as follows: $n-\mathrm{C}_{8}(\square), n-\mathrm{C}_{10}(\boldsymbol{\Delta}), n-\mathrm{C}_{12}$ $(\Delta), n-\mathrm{C}_{14}(+), n-\mathrm{C}_{16}(\square), n-\mathrm{C}_{18}(\diamond)$, and $n-\mathrm{C}_{20}(\bullet)$. The linear regression parameters for the correlations in Fig. 8 are listed in Table 5.

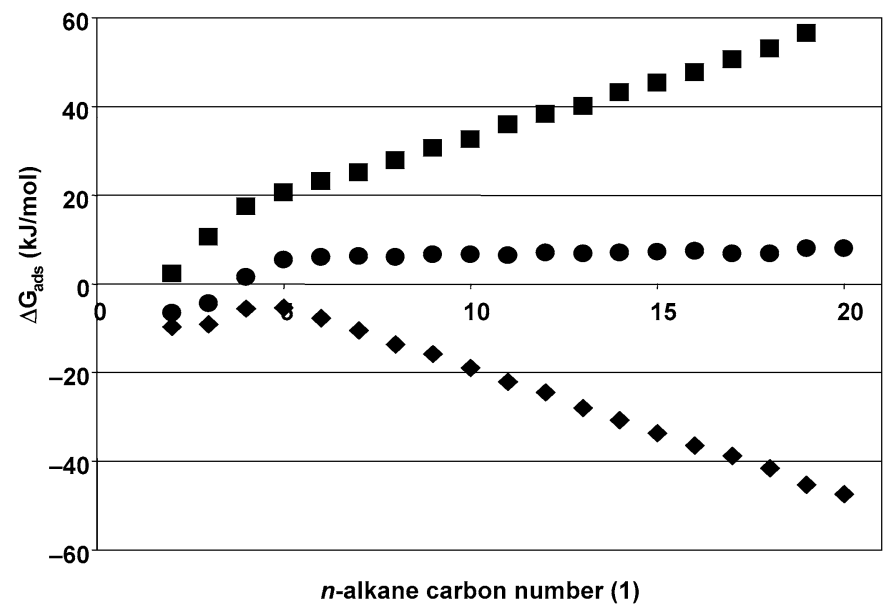

(a)

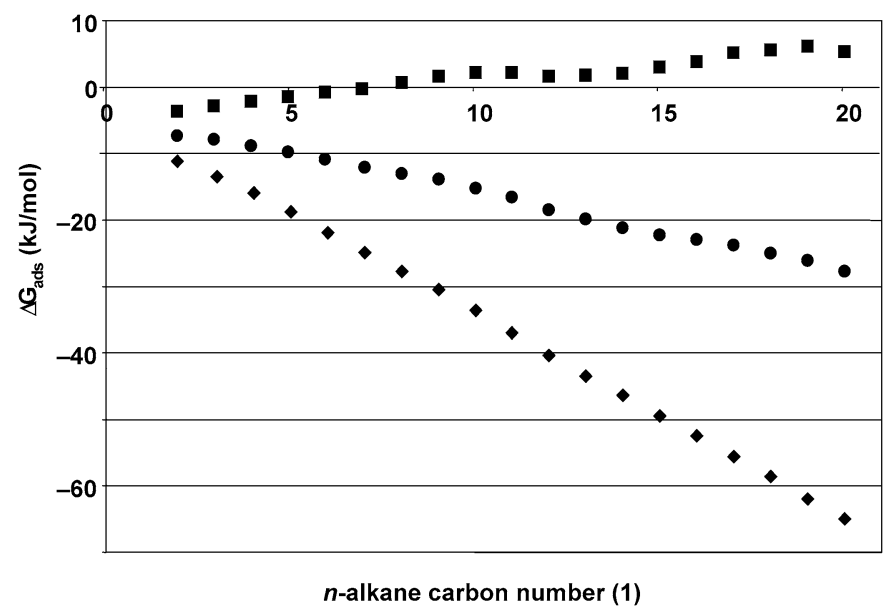

(b)

Fig. 9. (a) Variation of Gibbs free energy of adsorption, $\Delta G_{\text {ads }}(\mathrm{kJ} / \mathrm{mol})$, with carbon number (1) for FER-type zeolites and (b) for MFI-type zeolites at $600(\diamond), 775(\bullet)$, and $945 \mathrm{~K}(\mathbf{\square})$.

kanes. At severe catalytic cracking conditions, this can result in a cage effect [31], because it allows faster diffusing shortchain $n$-alkanes to react, penetrate, and clog FER-type channels before long-chain $n$-alkanes can do so. This improved understanding of cage effects may contribute to the successful use of this effect in commercial practice, and could be a first step toward length-selective hydrocracking [6].

\section{Acknowledgments}

These investigations were supported in part by the Netherlands Research Council for Chemical Sciences (CW) with financial aid from the Netherlands Technology Foundation, by the Netherlands Organization for Scientific Research (NWO) through PIONIER, by Chevron and by the Stichting Nationale Computer Faciliteiten (National Computing Facilities Foundation) through the use of their supercomputer facilities. The authors thank the European Commission for an ERG (to S.C.) and also thank C. Wilson, C.H. Roemkens, R. Krishna, A. Kuperman, S.I. Zones, and A.W. Burton for their comments on an earlier version of the manuscript. 


\author{
Appendix A. Reaction kinetics in the Henry and Langmuir \\ regimes
}

Description of adsorption effects in catalysis usually uses the Langmuir-Hinshelwood-Hougen-Watson approach [7,12-17]. This approach assumes that catalytic activity is directly proportional to the fractional loading of the acid sites. The fractional loading is then approximated with a Langmuir isotherm. If the rate of disappearance of reactant A with time, $t$ (s), in the adsorbed phase, $c_{\mathrm{A} \text { ads }}\left(\mathrm{mol} / \mathrm{m}_{\mathrm{ads}}^{3}\right)$, follows first-order kinetics, then the following equation describes the reaction rate on a zeolite pore volume basis:

$$
\frac{\mathrm{d} c_{\mathrm{A} \text { ads }}}{\mathrm{d} t}=-k^{\prime} c_{\mathrm{A} \text { gas }}=-k c_{\mathrm{A} \text { ads }}=-k c_{\mathrm{s}} \frac{K_{\mathrm{L}} c_{\mathrm{A} \text { gas }}}{1+K_{\mathrm{L}} c_{\mathrm{A} \text { gas }}} .
$$

In this equation, $k(1 / \mathrm{s})$ is the intrinsic reaction rate constant, $k^{\prime}\left(\mathrm{m}_{\mathrm{gas}}^{3} /\left(\mathrm{m}_{\mathrm{ads}}^{3} \mathrm{~s}\right)\right)$ is the observed first-order rate constant, $c_{\mathrm{s}}$ $\left(\mathrm{mol} / \mathrm{m}_{\text {ads }}^{3}\right)$ is the saturation concentration, $K_{\mathrm{L}}\left(\mathrm{m}_{\mathrm{gas}}^{3} / \mathrm{mol}\right)$ is the Langmuir constant, and $c_{\mathrm{A} \text { gas }}\left(\mathrm{mol} / \mathrm{m}_{\mathrm{gas}}^{3}\right)$ is the reactant gas-phase concentration. Usually the saturation loading of the acid sites is assumed to be directly proportional to that of the zeolite pores. It implies that the reaction rate is zero order in $\mathrm{A}$ at extremely high $\mathrm{A}$ loading $\left(K_{\mathrm{L}} c_{\mathrm{A} \text { gas }} \gg 1\right)$ and that the reaction rate is first order in $\mathrm{A}$ at extremely low A loading $\left(K_{\mathrm{L}} c_{\mathrm{A} \text { gas }} \ll 1\right)$.

Recent reviews of the $n$-alkane adsorption isotherms of various zeolites have shown that Langmuir isotherms describe adsorption inadequately in the extremely low loading (Henry) regime $[74,75]$. Accordingly, the Henry regime calls for a description of the kinetics of adsorption and reaction that uses Henry constants instead of the traditional Langmuir constants. In the Henry regime, gas-phase and adsorbed-phase concentrations ( $c_{\mathrm{A} \text { gas }}$ and $\left.c_{\mathrm{A} \text { ads }}\right)$ are related through the Henry law and through the ideal gas law. The Henry law states that the adsorbed phase loading of $\mathrm{A}, q_{\mathrm{A}}(\mathrm{mol} / \mathrm{kg})$ is directly proportional to its partial pressure, $p_{\mathrm{A}}(\mathrm{Pa})$,

$q_{\mathrm{A}}=K_{\mathrm{H}} p_{\mathrm{A}}$.

In this equation, $K_{\mathrm{H}}(\mathrm{mol} /(\mathrm{kg} \mathrm{Pa}))$ is the Henry constant. Multiplication with the zeolite framework density, $\rho\left(\mathrm{kg} / \mathrm{m}_{\text {ads }}^{3}\right)$, turns the loading, $q_{\mathrm{A}}$, into the adsorbed-phase concentration $c_{\mathrm{A} \text { ads }}$. The ideal gas law links pressure, $p_{\mathrm{A}}$, and gas-phase concentration, $c_{\mathrm{A} \text { gas. }}$ Thus, one can write

$c_{\mathrm{A} \text { ads }}=\rho q_{\mathrm{A}}=\rho K_{\mathrm{H}} R T c_{\mathrm{A} \text { gas }}$.

In this equation, $R(8.3144 \mathrm{~J} /(\mathrm{mol} \mathrm{K}))$ is the gas constant and $T(\mathrm{~K})$ is the absolute temperature. Provided that there is a large excess of acid sites compared with adsorbed reactants, substituting Eq. (A.3) into Eq. (A.1) links the observed and the intrinsic rate constants in the absence of diffusion limitations as

$\frac{\mathrm{d} c_{\mathrm{A} \text { gas }}}{\mathrm{d} t}=-\frac{k^{\prime}}{\rho K_{\mathrm{H}} R T} c_{\mathrm{A} \text { gas }}=-k c_{\mathrm{A} \text { gas }}$.

Equation (A.4) is the basis for Eq. (2). It implies that the observed variation in $k^{\prime}$ as a result of varying the $n$-alkane length is directly proportional to the variation in the $K_{\mathrm{H}}$ value and the intrinsic reactivity ( $k$ value) of the various $n$-alkanes.

\section{Appendix B. Diffusion-limited reaction kinetics in the Henry regime}

When the reaction is diffusion-limited, a mass balance across a film with thickness $x(\mathrm{~m})$ in the adsorbed phase describes that the flux of $\mathrm{A}$ into the film through diffusion equals the consumption of $\mathrm{A}$ inside the film through reaction [7]:

$D \frac{\mathrm{d}^{2} c_{\mathrm{A} \text { ads }}}{\mathrm{d} x^{2}}=k c_{\mathrm{A} \text { ads }}$.

In this equation, $D\left(\mathrm{~m}^{2} / \mathrm{s}\right)$ is the diffusion coefficient. To facilitate mathematical operations, it is convenient to define a Thiele modulus $\Phi(1)$ as [7]

$\Phi \equiv \delta \sqrt{\frac{k}{D}}$.

When $\Phi>2$, the reaction rate is much faster than the diffusion rate, so that no reactant reaches the catalyst core (at $x=\delta \mathrm{m}$ ). Assuming that the adsorbed-phase concentration at the interface, $c_{\mathrm{A} \text { ads i }}\left(\mathrm{mol} / \mathrm{m}^{3}\right)$, is in equilibrium with the gas phase $\left(c_{\mathrm{A} \text { ads }}=c_{\mathrm{A} \text { ads } \mathrm{i}}=\rho K_{\mathrm{H}} R T c_{\mathrm{A} \text { gas }}\right.$ at $\left.x=0 \mathrm{~m}\right)$ affords integration of differential Eq. (B.1), yielding [7]

$\frac{\mathrm{d} c_{\mathrm{A} \text { ads }}}{\mathrm{d} t}=\frac{k}{\Phi} c_{\mathrm{A} \text { ads }}=-\frac{1}{\delta} \sqrt{(k D)} c_{\mathrm{A} \text { ads }}$.

Using Eq. (A.3) to arrive at equations based on a gas-phase concentration yields

$\frac{\mathrm{d} c_{\mathrm{A} \text { gas }}}{\mathrm{d} t}=-\frac{1}{\delta} \sqrt{(k D)} c_{\mathrm{Agas}}=\frac{k^{\prime}}{\rho K_{\mathrm{H}} R T} c_{\mathrm{A} \text { gas }}$.

Equation (B.4) is the basis for Eq. (3). It implies that the observed rate constant $k^{\prime}$ contains information about both adsorption and diffusion properties. The observed variation in $k^{\prime}$ as a result of varying the $n$-alkane length is directly proportional to the $K_{\mathrm{H}} \sqrt{D}$ value of the $n$-alkanes and also to differences in intrinsic reactivity ( $k$ value) between the $n$-alkanes. For longer $n$-alkanes, differences in intrinsic reactivity $(k)$ are minimal. Fig. 8c illustrates this invariance of intrinsic reactivity $k$ with $n$-alkane length for the conversion in the absence of added hydrogen. A similar invariance was reported for $n$-alkane hydroconversion [18-20].

\section{References}

[1] B. Kovarik, Autom. History Rev. 32 (1998) 7-27; http://www.radford. edu/ wkovarik/papers/fuel.html.

[2] N.Y. Chen, Ind. Eng. Chem. Res. 40 (2001) 4157-4161.

[3] N.Y. Chen, J. Maziuk, A.B. Schwartz, P.B. Weisz, Oil Gas J. 66 (1968) 154-157.

[4] R.H. Heck, N.Y. Chen, Appl. Catal. A: Gen. 86 (1992) 83-99.

[5] R.H. Heck, N.Y. Chen, Ind. Eng. Chem. Res. 32 (1993) 1003-1006.

[6] J. Wei, Ind. Eng. Chem. Res. 33 (1994) 2467-2472.

[7] G.F. Froment, K.B. Bischoff, Chemical Reactor Analysis and Design, Wiley, New York, 1979, p. 800.

[8] M. Steijns, G.F. Froment, Ind. Eng. Chem. Prod. Res. Dev. 20 (1981) 660668.

[9] M.A. Baltanas, H. Vansina, G.F. Froment, Ind. Eng. Chem. Prod. Res. Dev. 22 (1983) 531-539.

[10] G.F. Froment, Catal. Today 1 (1987) 455-473.

[11] E.G. Derouane, J. Catal. 100 (1986) 541-544. 
[12] E.G. Derouane, Chem. Phys. Lett. 142 (1987) 200-204.

[13] E.G. Derouane, J.M. Andre, A.A. Lucas, J. Catal. 110 (1988) 58-73.

[14] E.G. Derouane, NATO ASI Series, Ser. B: Phys. 221 (1990) 225-239.

[15] W.O. Haag, Stud. Surf. Sci. Catal. 84 (1994) 1375-1394.

[16] G.C. Smith, Catalytic Cracking of $n$-Alkanes and $n$-Alkylbenzenes over H-ZSM-5 Zeolite, Massachusetts Institute of Technolgoy, Boston, 1993.

[17] J. Wei, Chem. Eng. Sci. 51 (1996) 2995-2999.

[18] B. Debrabandere, G.F. Froment, Stud. Surf. Sci. Catal. 106 (1997) 379389.

[19] J.F. Denayer, G.V. Baron, W. Souverijns, J.A. Martens, P.A. Jacobs, Ind. Eng. Chem. Res. 36 (1997) 3242-3247.

[20] J.W. Thybaut, G.B. Marin, G.V. Baron, P.A. Jacobs, J.A. Martens, J. Catal. 202 (2001) 324-339.

[21] J.A. van Bokhoven, B.A. Williams, W. Ji, D.C. Koningsberger, H.H. Kung, J.T. Miller, J. Catal. 224 (2004) 50-59.

[22] N.Y. Chen, Catal. Proc. Int. Congr. 5th 2 (1973) 1343-1351.

[23] N.Y. Chen, W.E. Garwood, Advan. Chem. Ser. 121 (1973) 575-582.

[24] N.Y. Chen, W.E. Garwood, J. Catal. 53 (1978) 284-285.

[25] N.Y. Chen, W.E. Garwood, Ind. Eng. Chem. Process Des. Dev. 17 (1978) 513-518.

[26] N.Y. Chen, W.E. Garwood, J. Catal. 52 (1978) 453-458.

[27] N.Y. Chen, J.L. Schlenker, W.E. Garwood, G.T. Kokotailo, J. Catal. 86 (1984) 24-31.

[28] N.Y. Chen, W.E. Garwood, Catal. Rev.-Sci. Eng. 28 (1986) 185-264.

[29] J.P. Giannetti, A.J. Perrotta, Ind. Eng. Chem. Proc. Design Dev. 14 (1975) 86-92.

[30] D.S. Santilli, S.I. Zones, Catal. Lett. 7 (1990) 383-387.

[31] Y. Lu, M.-Y. He, X.-T. Shu, B.-N. Zong, Energy Fuels 17 (2003) 10401042.

[32] P.B. Weisz, V.J. Frilette, J. Phys. Chem. 64 (1960) 382-383.

[33] P.B. Weisz, Pure Appl. Chem. 52 (1980) 2091-2103.

[34] S.M. Csicsery, J. Catal. 23 (1971) 124-130.

[35] S.M. Csicsery, ACS Monogr. 171 (1976) 680-713.

[36] A. van de Runstraat, J. van Grondelle, R.A. van Santen, Ind. Eng. Chem. Res. 36 (1997) 3116-3125.

[37] F. Eder, J.A. Lercher, J. Phys. Chem. 100 (1996) 16460-16462.

[38] F. Eder, M. Stockenhuber, J.A. Lercher, J. Phys. Chem. B 101 (1997) 5414-5419.

[39] F. Eder, J.A. Lercher, J. Phys. Chem. B 101 (1997) 1273-1278.

[40] A. Jentys, J.A. Lercher, Stud. Surf. Sci. Catal. 137 (2001) 345-386.

[41] D.W. Sundstrom, F.G. Krautz, J. Chem. Eng. Data 13 (1968) 223-226.

[42] C.N. Satterfield, J.K. Smeets, AIChE J. 20 (1974) 618-619.

[43] R. Krishna, B. Smit, S. Calero, Chem. Soc. Rev. 31 (2002) 185-194.

[44] J.F.M. Denayer, K. De Meyer, J.A. Martens, G.V. Baron, Angew. Chem. Int. Ed. 42 (2003) 2774-2777.

[45] J.F.M. Denayer, R.A. Ocakoglu, W. Huybrechts, B. Dejonckheere, P. Jacobs, S. Calero, R. Krishna, B. Smit, G.V. Baron, J.A. Martens, J. Catal. 220 (2003) 66-73.

[46] J.F. Denayer, A.R. Ocakoglu, B.A. De Jonckheere, J.A. Martens, J.W. Thybaut, G.B. Marin, G.V. Baron, Int. J. Chem. React. Eng. 1 (2003), no pp. given.

[47] S. Calero, D. Dubbeldam, R. Krishna, B. Smit, T.J.H. Vlugt, J.F.M. Denayer, J.A. Martens, T.L.M. Maesen, J. Am. Chem. Soc. 126 (2004) $11377-11386$

[48] R. Krishna, R. Baur, Chem. Eng. Sci. 60 (2005) 1155-1166.

[49] N.Y. Chen, S.J. Lucki, E.B. Mower, J. Catal. 13 (1969) 331-334.

[50] R.L. Gorring, J. Catal. 31 (1973) 13-26.

[51] E. Ruckenstein, P.S. Lee, Phys. Lett. A 56A (1976) 423-424.

[52] J.M. Nitsche, J. Wei, AIChE J. 37 (1991) 661-670.

[53] R. Tsekov, E. Ruckenstein, J. Chem. Phys. 100 (1994) 3808-3812.

[54] K. Yoo, R. Tsekov, P.G. Smirniotis, J. Phys. Chem. B 107 (2003) $13593-$ 13596.

[55] R. Tsekov, P.G. Smirniotis, J. Phys. Chem. B 102 (1998) 9385-9391.

[56] Y. Frenkel, T. Kontorova, Phys. Zeitschrift der Sowjetunion 13 (1938) 110.
[57] F.D. Magalhães, R.L. Laurence, W.C. Conner, AIChE J. 42 (1996) 68-86.

[58] C.L. Cavalcante Jr, M. Eic, D.M. Ruthven, M.L. Occelli, Zeolites 15 (1995) 293-307.

[59] D. Dubbeldam, B. Smit, J. Phys. Chem. B 107 (2003) 12138-12152.

[60] D.M. Ruthven, J. Phys. Chem. B 108 (2004) 16328-16329.

[61] D. Dubbeldam, T.L.M. Maesen, B. Smit, J. Phys. Chem. B 108 (2004) 16330.

[62] D. Dubbeldam, E. Beerdsen, S. Calero, B. Smit, Proc. Nat. Acad. Sci. 102 (2005) $12317-12320$

[63] M. Schenk, B. Smit, T.J.H. Vlugt, T.L.M. Maesen, Angew. Chem. Int. Ed. 40 (2001) 736-739.

[64] M. Schenk, S. Calero, T.L.M. Maesen, T.J.H. Vlugt, L.L. van Benthem, M.G. Verbeek, B. Schnell, B. Smit, J. Catal. 214 (2003) 92-103.

[65] E. Fach, R. Kristovich, J.F. Long, W.J. Waldman, P.K. Dutta, M.V. Williams, Environ. Int. 29 (2003) 451-458.

[66] H.E. Robson, G.P. Hamner, W.F. Arey Jr., Adv. Chem. Ser. 102 (1971) 417-425.

[67] G.H. Kuehl, Mol. Sieves, Pap. Conf. (1968) 85-91.

[68] M.-J. Diaz-Cabanas, P.A. Barrett, M.A. Camblor, Chem. Commun. (Cambridge) (1998) 1881-1882.

[69] S.I. Zones, L.-T. Yuen, S.J. Miller, WO2003020641 (2003), to Chevron U.S.A. Inc., USA.

[70] C. Baerlocher, W.M. Meier, D.H. Olson, Atlas of Zeolite Framework Types, Elsevier, Amsterdam, 2001, 1-229.

[71] N.Y. Chen, W.E. Garwood, F.G. Dwyer, Shape Selective Catalysis in Industrial Applications, Chem. Ind. (Dekker), New York, 1996, p. 52.

[72] D. Dubbeldam, S. Calero, T.L.M. Maesen, B. Smit, Angew. Chem. Int. Ed. 42 (2003) 3624-3626.

[73] D. Dubbeldam, S. Calero, T.L.M. Maesen, B. Smit, Phys. Rev. Lett. 90 (2003), 245901/1-01/4.

[74] D. Dubbeldam, S. Calero, T.J.H. Vlugt, R. Krishna, T.L.M. Maesen, E. Beerdsen, B. Smit, Phys. Rev. Lett. 93 (2004), 088302/1-02/4.

[75] D. Dubbeldam, S. Calero, T.J.H. Vlugt, R. Krishna, T.L.M. Maesen, B. Smit, J. Phys. Chem. B 108 (2004) 12301-12313.

[76] A.G. Bezus, A.V. Kiselev, A.A. Lopatkin, P.Q. Du, J. Chem. Soc., Faraday Trans. 2: Mol. Chem. Phys. 74 (1978) 367-379.

[77] R.L. June, A.T. Bell, D.N. Theodorou, J. Phys. Chem. 96 (1992) $1051-$ 1060.

[78] B. Smit, J.I. Siepmann, J. Phys. Chem. 98 (1994) 8442-8452.

[79] J.S. Chickos, W. Hanshaw, J. Chem. Eng. Data 49 (2004) 77-85.

[80] T.L.M. Maesen, M. Schenk, T.J.H. Vlugt, B. Smit, J. Catal. 203 (2001) 281-291.

[81] E. Beerdsen, B. Smit, D. Dubbeldam, Phys. Rev. Lett. 93 (2004), 248301/ $1-01 / 4$.

[82] E.B. Webb III, G.S. Grest, J. Chem. Phys. 116 (2002) 6311-6321.

[83] J. Kärger, D.M. Ruthven, Diffusion in Zeolites and Other Microporous Solids, Wiley, New York, 1992.

[84] E.B. Webb III, G.S. Grest, M. Mondello, J. Phys. Chem. B 103 (1999) 4949-4959.

[85] B.P. Pelrine, N.Y. Chen, US4222855 (1980), to Mobil Oil Corp., USA.

[86] BHC Winquist US4343692 (1982), to Shell Oil Co., USA.

[87] Y. Jin, A. Auroux, J.C. Vedrine, Appl. Catal. 37 (1988) 1-19.

[88] T. Ito, M.A. Springuel-Huet, J. Fraissard, Zeolites 9 (1989) 68-73.

[89] S.B. Rice, Am. Mineral. 80 (1995) 930-936.

[90] A. Corma, V. Gonzalez-Alfaro, A.V. Orchilles, Appl. Catal. A: Gen. 187 (1999) 245-254.

[91] S. van Donk, F.M.F. de Groot, O. Stephan, J.H. Bitter, K.P. de Jong, Chem. A: Eur. J. 9 (2003) 3106-3111.

[92] E. Benazzi, L. Leite, N. Marchal-George, H. Toulhoat, P. Raybaud, J. Catal. 217 (2003) 376-387.

[93] H. Toulhoat, P. Raybaud, E. Benazzi, J. Catal. 221 (2004) 500-509.

[94] W.J.M. van Well, X. Cottin, J.W. de Haan, R.A. van Santen, B. Smit, Angew. Chem. Int. Ed. 37 (1998) 1081-1083. 